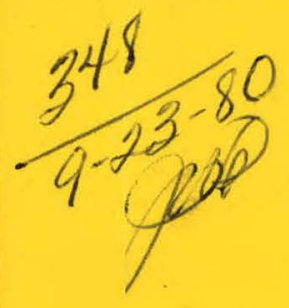

\title{
THREE COMPUTER CODES TO READ, PLOT, AND TABULATE OPERATIONAL TEST-SITE RECORDED SOLAR DATA
}

By Stephen D. Stewart, Robert J. Sampson, Jr., Richard E. Stonemetz, and Sandra L. Rouse, Systems Analysis and Integration Laboratory

National Aeronautics and Space Administration

George C. Marshall Space Flight Center, Alabama 35812

July 1980

For the U. S. Department of Energy

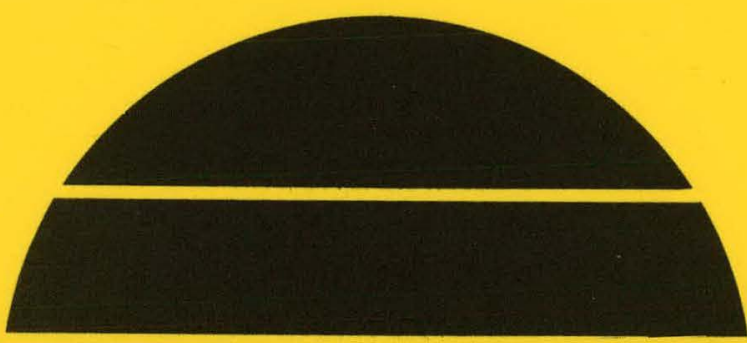

\section{U.S. Department of Energy}




\section{DISCLAIMER}

This report was prepared as an account of work sponsored by an agency of the United States Government. Neither the United States Government nor any agency Thereof, nor any of their employees, makes any warranty, express or implied, or assumes any legal liability or responsibility for the accuracy, completeness, or usefulness of any information, apparatus, product, or process disclosed, or represents that its use would not infringe privately owned rights. Reference herein to any specific commercial product, process, or service by trade name, trademark, manufacturer, or otherwise does not necessarily constitute or imply its endorsement, recommendation, or favoring by the United States Government or any agency thereof. The views and opinions of authors expressed herein do not necessarily state or reflect those of the United States Government or any agency thereof. 


\section{DISCLAIMER}

Portions of this document may be illegible in electronic image products. Images are produced from the best available original document. 


\begin{tabular}{|c|c|}
\hline $\begin{array}{l}\text { 1. REPORT NO. } \\
\text { DOE/ NASA TM-78293 }\end{array}$ & 3. RECIPIENT'S CATALOG NO. \\
\hline \multirow{2}{*}{$\begin{array}{l}\text { 4. TITLE AND SUBTITLE } \\
\text { Three Computer Codes to Read, Plot, and Tabulate Operational } \\
\text { Test-Site Recorded Solar Data }\end{array}$} & $\begin{array}{l}\text { 5. REPORT DATE } \\
\text { July } 1980\end{array}$ \\
\hline & 6. PERFORMING ORGANIZATION CIIOE \\
\hline $\begin{array}{l}\text { 7. AUTHOR(S) Stephen D. Stewart, Robert J. Sampson, Jr., } \\
\text { Richard E. Stonemetz. and Sandra L. Rouse }\end{array}$ & 8. PERFORMING ORGANIZATION REPORT \# \\
\hline \multirow{3}{*}{$\begin{array}{l}\text { 9. PERFORMING ORGANIZATION NAME AND ADDRESS } \\
\text { George C. Marshall Space Flight Center } \\
\text { Marshall Space Flight Center, Alabama } 35812\end{array}$} & 10. WORK UNIT, NO. \\
\hline & 11. CONTRACT OR GRANT NO. \\
\hline & 13. TYPE OF REPORI \& PERIOD COVERED \\
\hline \multirow{2}{*}{$\begin{array}{l}\text { 12. SPONSORING AGENCY NAME AND ADDRESS } \\
\text { National Aeronautics and Space Administration } \\
\text { Washington, D. C. } 20546\end{array}$} & Technical Memorandum \\
\hline & 14. SPONSORING AGENCY COOE \\
\hline
\end{tabular}

Prepared by Systems Analysis and Integration Laboratory

16. ABSTRACT

A computer program, TAPFIL, has been developed by MSFC to read data from an IBM 360 tape for use on the PDP 11/70. The information (insolation, flowrates, temperatures, etc. from 48 operational solar heating and cooling test sites is stored on the tapes. Two other programs, CHPLOT and WRTCNL, have been developed to plot and tabulate the data. These data will be used in the evaluation of collector efficiency and solar system performance.

This report describes the methodology of the programs, their inputs, and their outputs.

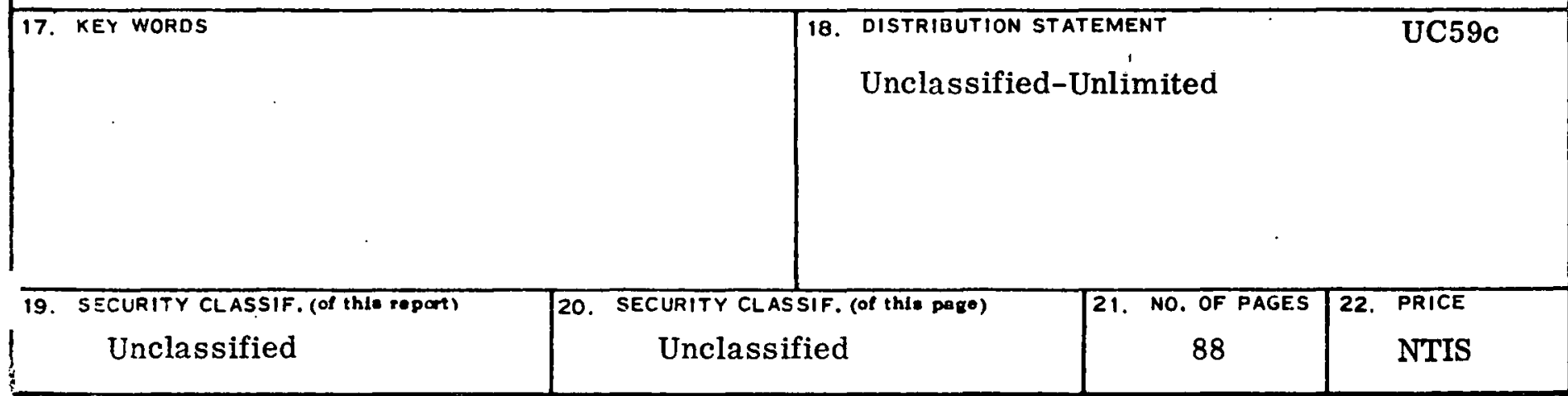


THIS PAGE

\section{WAS INTENTIONALLY LEFT BLANK}


TABLE OF CONTENTS

Page

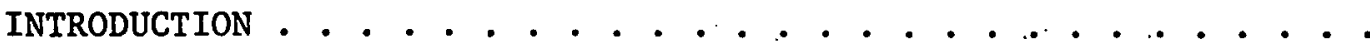

I. DATA SOURCE . . . . . . . . . . . . . . . . 1

A. Byte Locations . . . . . . . . . . . . 2

B. System Subtypes . . . . . . . . . ..... 3

C. Source Access Arrangement ............ 3

II. PROGRAM USAGE ...................... . . . 5

A. TAPFIL . . . . . . . . . . . . . . 5

B. CHPLOT ................... 8

C. WRTCNI...................... . 13

III. PROGRAM SOFTWARE IMPLEMENTATION . . . . . . . . . . . 14

A. Data Conversion Routines . . . . . . . . . 14

B. TEKPLOT Library Routines . . . . . . . . . 15

C. UTILITIES Library Routines . . . . . . . . . . 17

Appendix A- Sample Problem . . . . . . . . . . . . . . . 19

Appendix B- Flowcharts and Reference Tables . . . . . . . . . 27

Appendix C- TAPFIL Source Listing . . . . . . . . . . . 31

Appendix D- CHPLOT Source Listing . . . . . . . . . . . 53

Appendix E- WRTCNL Source Listing . . . . . . . . . . . . 81

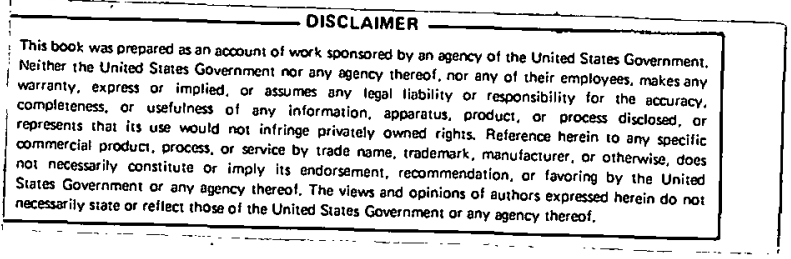




\section{LIST OF ILLUSTRATIONS}

Figure

Title

Page

1.

IBM 360 Tape Data Arrangement .......

3

2.

3.

Sample IPCL . . . . . . . . . . .

4.

TAPFIL Screen Display ............

6

5.

TAPFIL Time Profile............

7.

CHPLOT Screen Display . . . . . . . . . 9

6.

Data Plot . . . . . . . . . .

10

7.

Plotting Options ............

11

8.

Scaling Option Display . . . . . . . .

11

9.

Scaled Plot..............

12

10 .

WRTCNL Screen Display . . . . . . . .

13 


\section{INTRODUCTION}

Under contract with the Department of Energy, the National Aeronautics and Space Administration is managing 48 operational solar heating and cooling. test sites (OTS) and numerous large commercial systems. The sites are expected to provide information which will help engineers and designers evaluate the solar system's effectiveness in (1) reducing fossil fuel consumption and (2) maintaining design performance goals.

The information from these operational test sites (OTS) is provided as a large mass of data (insolation, flow rates, temperatures, etc.) stored on tape. In order to attain adequate engineering assessments of these systems, procedures must be developed to analyze the data on a real time basis. This report presents a detailed discussion of three computer programs (TAPFIL, CHPLOT, WRTCNL) developed by MSFC to read the OTS site data tapes and put the data in a form usable with other solar heating and cooling system analysis computer programs. These programs utilize the MSFC Systems Analysis and Integration Laboratory's PDP 11/70 computer facility. TAPFIL verifies the analytical methodology, CHPLOT plots the site data for examination of system/subsystem trends, and WRTCNL lists the data in tabular form.

Implementation of the program code on another computer system would be subject to an understanding of the program execution and the software capabilities of that system. The computer code development procedures are presented and discussed in such a manner as to prepare the reader to utilize this program code on any computer which has adequate capabilities.

\section{DATA SOURCE}

Each OTS solar system built under MSFC management utilizes a site data acquisition system.(SDAS) developed by IBM. The SDAS's are designed to retrieve raw data from 48 site measurements every 5 minutes and 20 seconds continuously. Several large OTS systems require more than 48 measurements of data to determine total system performance and require two SDAS's. This allows a maximum of 96 channels of site data to be retrieved. When two SDAS's are used at one site, two methods are used to join them together. One method is to connect the two of them to one clock so that the measurements may be sent to the central data processing facility in time sequence. The other method is to connect each SDAS to a separate clock, thus creating two time profiles which must be sorted and merged at the central data processing facility to obtain a time sequence.

The distinction between which type of time profile is created at a site is made by the system subtype. There are five subtypes. The subtype is determined from reading the IBM 360 data tapes. These tapes contain EBCDIC characters in a certain order according to subtype. These characters are sequentially stored in 62 records ( 210 bytes long) per data block of 13020 bytes. Each record contains 
time information, site identification information and 48 channels of data. The order of the data arrangement and time profile is defined below according to subtype. The arrangement of the data on the tape is shown in Figure 1.

\section{SUBTYPE \\ 1 \\ DATA ACQUISITION \\ One 48 channel SDAS}

\section{CHARACTER REPRESENTATION}

- Byte 1: No significant use

- Bytes 2-4: 3 digit Site ID number

- Bytes 5-16: Year, Month, Day, Hour, Minute, Seconds

For examp1e - YYMMDDHHNNSS is represented by Bytes $5,6, \ldots \ldots \ldots 15,16$. If date and time were $9 / 1 / 79$ and $10: 32: 58$, the tape would yield the following Byte representation 790901103258 (Bytes 5-16)

- Byte 17: System Subtype

- Byte 18: No significant use

- Bytes 19-210: 48 4-byte hexadecimal EBCDIC words representing channels 1-48

(There is no subtype 2)

$3 \quad$ 1st 48 channe1 SDAS of sorted and merged time profile

$4 \quad$ 2nd 48 channel SDAS of sorted and merged time profile SDAS of connected time profile.

Same as above except always used in conjunction with sybtype 4. Bytes 19-210 represent channels $1-48$.

Same as above except always used with subtype 3 . Bytes 19-210 represent channe1s 49-96.

Same as above except always used with subtype 6 . Bytes 19-210 represent channels 1-48.

Same as above except used with subtype 5 . 2nd 48 channel SDAS of connected time profile. 
These records are stored in a data block. Subtype 1 records, utilizing one SDAS to retrieve data, are stored one record at a time with each time point being 5 minutes and 20 seconds apart. Subtype 3 records should be read immediately preceeding subtype 4 records. These two subtypes should have the exact same time point. The subtype 4 record should then be followed by another subtype 3 record with a new time point 5 minutes and 20 seconds later and continue in this subtype 3 subtype 4 sequential manner until completion of 270 output records. In some instances however, contiguous records of subtype 3 or subtype 4 may be encountered. In these instances, the contiguous subtype records are not stored and the number of output records will be less than 270. Subtypes 5 and 6 are read and stored exactly the same as subtypes 3 and 4 except no contiguous records will be encountered.

All the above mentioned subtypes are written on 9-track data tapes by an IBM 360 computer at a density of 1600 bits per inch (BPI) with one end-of-file (EOF) written after each month of site data.

Each OTS has an Instrumentation Program and Components List (IPCL) which is used to correlate the channel number to the actual measurement at the site. Listed in the IPCL are the channel numbers, the measurement numbers, the operating ranges, and the names of each measurement. Once the IBM data tape has been successfully read and the data stored, the IPCL is used to determine which measurements are needed for calculations and plots. A sample. IPCL can be found in Figure 2. The data read from the IBM tape is stored by channel number in a data file. This will allow computer programs to be developed that do certain required calculations dependent upon a set of input channel numbers. Since every operational test site has a different channel orientation, these programs can be used to analyze and/or evaluate OTS systems according to the input channel numbers: This type of data storage (direct access unformatted) was chosen because it requires very little disk storage space compared to other types of storage, and is easily accessible, in that no data formatting is required.

We have discussed the formulation of the data source (IBM 360 OTS Tapes), the tape format, the storage of the source data on the PDP $11 / 70$ system disk, and the use of the IPCL to determine channel information for analysis and plotting. With this background, the specific programs used to read, convert and analyze the source data will be discussed next.

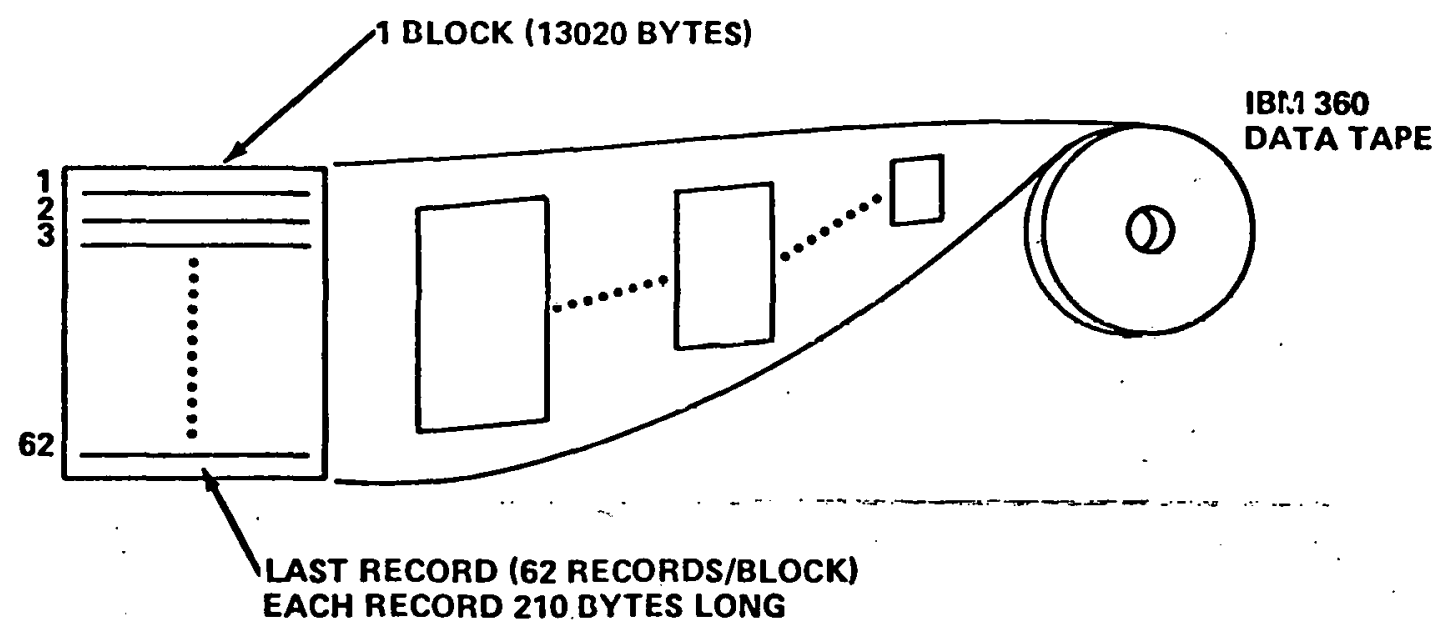

FIGURE 1. IBM 360 TAPE DATA ARRANGEMENT 
FIGURE 2. SAMPLE IPCL

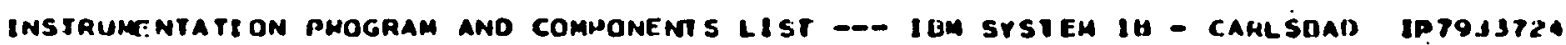

herght HY CHANNEl assignhLNT

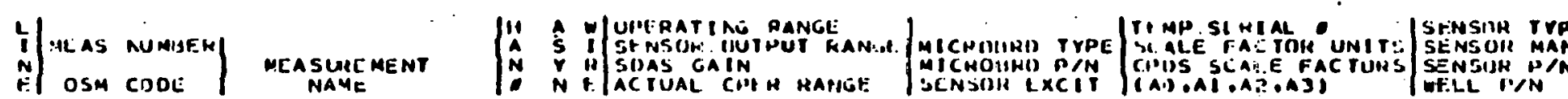

SRINSIMA TYPE ENSOIl MANUFACT

$18-3 \underset{0-100}{308100} \mathrm{migF}_{\mathrm{MV}}$

| NOYES

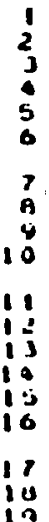

1001

PUITEAT COLL

PUIL TREP -

11111360
$79329 \times 0$

- 300-0JU6 CHW PAC-tEAT

1050

Uul' FLCII

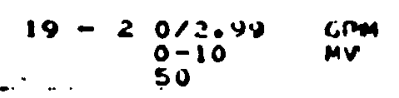

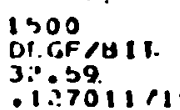

0.1270119190

Pat

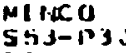

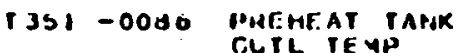

2001

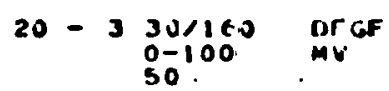

STRAIGHT
TY IOUAS

(1)M/AI I

Sistors

idusaubetior suct

FLII MITER

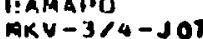

.990 -5 voc

litiobut

$1: 023$

$0.1265014 n$

0.0009405

SPOOz-0.2AS SPAPL

$21-2 \underset{\substack{N \\ N / A}}{N / A}$

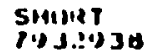

$N / A$

N/A

Ts02-004e'K DHW TEMP

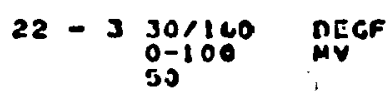

IincugF,

II if Jif

is: 93

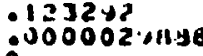

2.201

$23-2 \underset{\substack{M / A \\ \text { SOA }}}{M / A}$

silume

SPOOJ-00UL SPAHE

N/A

W/A

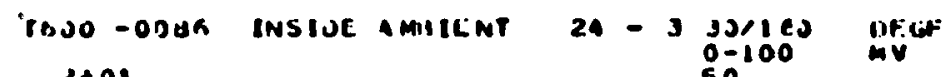

皮

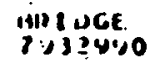

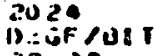

35.08

$0.1275+1102$

MINC

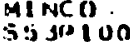

F.20

$\underset{n<A}{n<1}$

MIPICO

S5 3111010
F 2031170

(1)

N/A

Aif NCO

sisto 


\section{PROGRAM USAGE}

The following three programs are designed to be run on the MSFC PDP $11 / 70$, utilizing FORTRAN IV PLUS. CHPLOT and WRTCNL can be run only after a direct access unformatted file has been created by TAPFIL.

Appendix A contains a sample problem utilizing all three programs, An OTS site contracted by WORMSER and located in Columbia, S.C. is analyzed in this problem. Appendix $B$ contains flowcharts of the three programs, utilizing only the main subroutines. The functions performed by these subroutines are also listed in this appendix. A FORTRAN program listing for TAPFIL can be found in Appendix C, for CHPLOT in Appendix D, and for WRTCNL in Appendix E.

A brief description concerning the operation of these programs will now be presented.

\section{A. TAPFIL OPERATIONAL PROCEDURES}

The program TAPFIL is designed to create a direct access unformatted file from an IBM 360 tape. This file can then be used with the channel plotting program CHPLOT and the tabulation program WRTCNL, using the PDP 11/70. Due to the software used in the program, TAPFIL must be run from a TEKTRONIX 4014 Demand Terminal.

After program execution has begun, the first statement of Figure 3 will appear on the screen. The first user input will be the number of channels at the site. To ensure program execution, 48 is the miminum number that can be entered. The user should enter 48 even if the site actually has fewer than 48 channels. If the site has more than 48 channels, the input should be in increments of 16 , ranging from 48 to 96 . The maximum number that can be input is 96 , as this is the number of channels on two SDAS's.

The second user input is the desired date of data to be retrieved. This should be entered as MO DA YR. The program searches through the time profile on the tape, finds the date input by the user, and sets flags to begin output to the system disk.

The next user input is the data file name. This name should have a maximum of 29 characters. The convention used at MSFC is to enter the two digit site number with an "s" to indicate site, then the date as MODAYR, followed by .DAT to indicate a data file. For example, if the user wants to use the data for June 13, 1980 from OTS site $\|_{12}$, the input will be 12S061380.DAT.

The fourth user input will be the file number of the data date. The months contained on a tape are listed on the front of that tape. To obtain the file number, count the months from the start of the list until the desired month is reached, This is the file number. 
The last user input will be a decision as to whether or not a line printer time profile is wanted. After all inputs are complete, an output statement will appear stating that the data is being retrieved.

The next output on the screen will be a time profile, as shown in Figure 4. If the user has so requested, this time profile will also be output to the line printer. Also written will be a statement telling how many records the data is stored in. If an error is encountered during execution, various error. messages w111 be printed to inform the user.

Once the time profile has been written, the program is in pause mode. The user must depress any key to continue program execution.

A statement will then appear requiring user input as to whether more data is to be retrieved. If so, the statements of Figure 3 will be repeated, with the exception of the headings and the question concerning the number of channels at the site. If no more data is to be retrieved, a statement will appear stating that the tape is being rewound.

The TAPFIL program has now created direct access unformatted files. These files are ready for use with CHPLOT and WRTCNL to analyre the site data.

TAPE TO FILE PROGRAM

SYSTEMS REQUIREMENTS BRANCH

SYSTEMS ANALYSIS AND INTEGRATION LABORATORY

ENTER THE NUMBER OF CHANMELS AT SITE

48

ENTER DESIRED DATE OF DATA TO BE RETRIEUED ASi HO DA VR

061579

ENTER DATA FILE NAME

035061579. DAT

ENTER THE FILE MUMBER OF THE DATA DATE .

16

DO YOU UANT A LINE PRINTER TIME PROFILE ? (1-YES,2-NO)

2

DATA IS NOU BEING RETRIEUED

FIGURE 3. TAPFIL SCREEN DISPIAY 
FIGURE 4.

TPFIL TIME PROFILE

\begin{tabular}{|c|c|c|c|c|c|}
\hline $\begin{array}{l}6 / 15 \\
6 / 15 \\
6 / 15 \\
6 / 15 \\
6 / 15 \\
6 / 15 \\
6 / 15 \\
6 / 15 \\
6 / 15 \\
6 / 15 \\
6 / 15 \\
6 / 15 \\
6 / 15 \\
6 / 15 \\
6 / 15 \\
6 / 15 \\
6 / 15 \\
6 / 15 \\
6 / 15 \\
6 / 15 \\
66 / 15 \\
6 / 15 \\
6 / 15 \\
6 / 15 \\
6 / 15 \\
6 / 15 \\
6 / 15 \\
6 / 15 \\
6 / 15 \\
6 / 15 \\
6 / 15 \\
6 / 15 \\
6 / 15 \\
6 / 15 \\
6 / 15 \\
6 / 15 \\
6 / 15 \\
6 / 15 \\
6 / 15 \\
6 / 15 \\
6 / 15\end{array}$ & 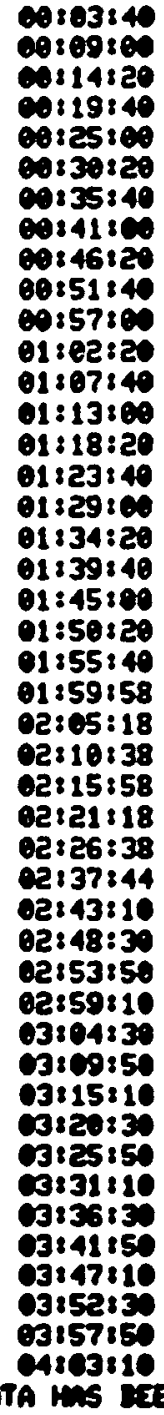 & $\begin{array}{l}66 / 15 \\
66 / 15 \\
66 / 15 \\
06 / 15 \\
66 / 15 \\
06 / 15 \\
6 / 15 \\
66 / 15 \\
66 / 15 \\
66 / 15 \\
66 / 15 \\
66 / 15 \\
66 / 15 \\
66 / 15 \\
66 / 15 \\
66 / 15 \\
66 / 15 \\
66 / 15 \\
66 / 15 \\
66 / 15 \\
66 / 15 \\
06 / 15 \\
66 / 15 \\
66 / 15 \\
66 / 15 \\
66 / 15 \\
66 / 15 \\
66 / 15 \\
66 / 15 \\
6 / 15 \\
66 / 15 \\
65 / 15 \\
66 / 15 \\
6 / 15 \\
6 / 15 / 15 \\
66 / 15 \\
6 / 15 \\
66 / 15\end{array}$ & 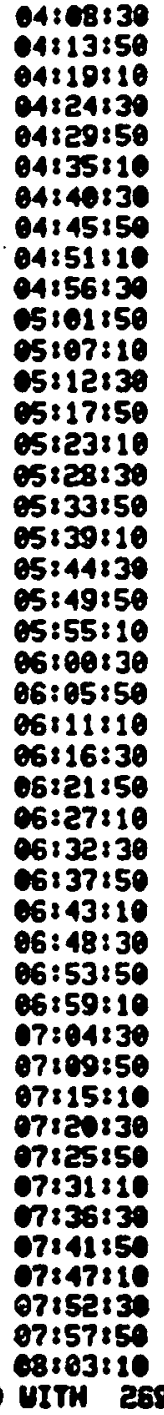 & $\begin{array}{l}6 / 15 \\
6 / 15 \\
6 / 15 \\
6 / 115 \\
66 / 15 \\
66 / 15 \\
6 / 15 \\
6 / 15 \\
6 / 15 \\
6 / 15 \\
66 / 15 \\
66 / 15 \\
66 / 15 \\
66 / 15 \\
66 / 15 \\
66 / 15 \\
66 / 15 \\
66 / 15 \\
66 / 15 \\
66 / 15 \\
66 / 15 \\
66 / 15 \\
66 / 15 \\
66 / 15 \\
66 / 15 \\
66 / 15 \\
66 / 15 \\
66 / 15 \\
66 / 15 \\
66 / 15 \\
66 / 15 \\
66 / 15 \\
66 / 15 \\
06 / 15 \\
06 / 15 \\
66 / 15 \\
66 / 15 \\
66 / 15\end{array}$ & 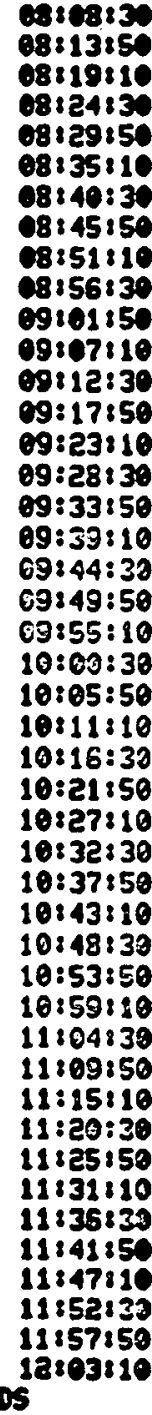 \\
\hline
\end{tabular}

\begin{tabular}{|c|c|c|c|c|c|}
\hline $\begin{array}{l}6 / 15 \\
6 / 15 \\
6 / 15 \\
6 / 15 \\
6 / 15 \\
6 / 15 \\
6 / 15 \\
6 / 15 \\
6 / 15 \\
6 / 15 \\
6 / 15 \\
6 / 15 \\
6 / 15 \\
6 / 15 \\
6 / 15 \\
6 / 15 \\
5 / 15\end{array}$ & 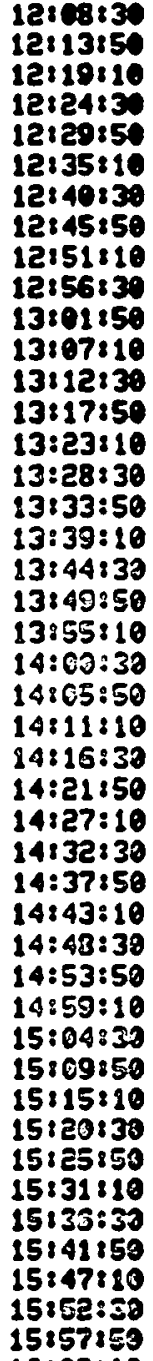 & 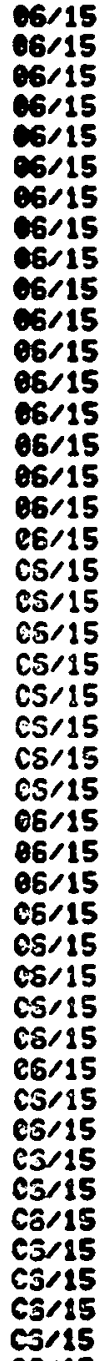 & 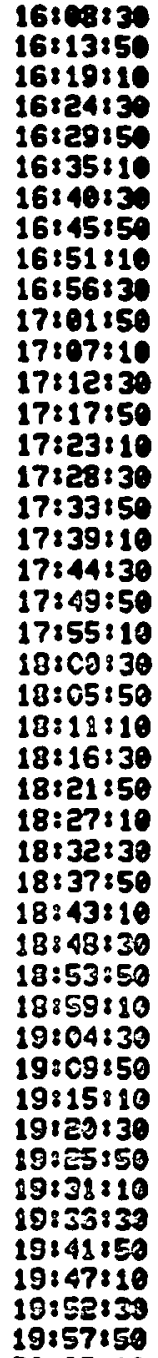 & $\begin{array}{l}06 \\
66 \\
06 \\
06 \\
66 \\
66 \\
06 \\
66 \\
06 \\
06 \\
06\end{array}$ & $\begin{array}{l}20 \\
20 \\
20 \\
20 \\
20 \\
20 \\
20 \\
20 \\
20 \\
21 \\
21 \\
21 \\
21 \\
21 \\
21 \\
21 \\
21 \\
21 \\
21 \\
21 \\
22 \\
22 \\
22 \\
22 \\
22 \\
22 \\
22 \\
22 \\
22\end{array}$ \\
\hline
\end{tabular}

C5/15 15857859

C5/15 $19: 5785$

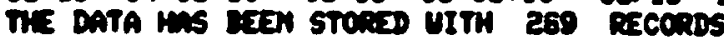




\section{B. CHPLOT OPERATIONAL PROCEDURES}

The purpose of CHPLOT is to plot the data stored in a file created by TAPFIL. The program has the capability to plot as many as five plots on one graph. CHPLOT must be run from a TEKTRONIX 4014 Demand Terminal due to the software used in the program.

When program execution has begun, the first lines of Figure 5 will appear on the screen. The first user input is the file name in which the data to be plotted is stored. This should be the name of a file created by TAPFIL. The second user input is the number of plots desired on the graph. The maximum number allowable is five. The next two user inputs are the captions to be written at the bottom and on the left margin of the plot. The first caption allows 49 characters to be output; the second caption allows 16 characters.

The fifth user input is the channel numbers to be plotted, along with appropriate units. The IPCL should be referenced to obtain the correct channel number of the measurement desired. After entering a channel number, the next input should be the mnemonic name and the units of that measurement. The carriage return should be depressed after both the name and the units. This is repeated until the desired number of channel numbers and units has been input.

The last input shown on Figure 5 is the number of channels of data at that site. This is subject to the same restrictions specified in the description of TAPFIL. After all user inputs are completed, an output statement will appear stating that the data is being retrieved.

After the data has been retrieved, a plot similar to the one in Figure 6 will appear on the screen. The grid is designed to fit onto a regular $8-1 / 2$ by 11 inch sheet after xeroxing for use in reports to which these data are pertinent.

When the plot is completed, the program is in pause mode. The user must depress any key to continue execution. The next output to the screen is shown in Figure 7. This display gives the user a choice of five options for plotting. With the exception of option 2, the scallng optlun, Llie options are self-cxplanatory. The user must make his decision, enter the number of that option, and depress the carriage return.

An example of the scaling options display is shown in Figure 8. This option gives the user the capability of windowing in on a certain section of the plot that was just made. The first input to the scaling option (XMAX) is the maximum abscissa value to be plotted; the second is the smallest abscissa value to be plotted. The third and fourth inputs are the maximum and minimum values for the ordinate to be plotted. After entering, the last value in the scaling option, the plot in Figure 9 will appear on the screen. The plot will have the user input maximum and minimum values at the appropriate locations on the grid. After this plot has been completed, the program is in pause mode. Depressing a key will return control to the plotting options in Figure 7. 


\section{El 55 ChanNel plotting program}

\section{EMTER PLOT FILE NAME \\ OJSO61579.DAT}

ENTER NO. OF PLOTS ON THIS GRAPH (MAX-5)

2

ENTER PLOT CAPTION (49 CHARACTERS)

UORMSER $6 / 15 / 79$

ENTER CAPTION FOR LEFT SIDE OF PLOT

TERPERATURE

ENTER CHAMNEL NO. AMD UNITS

12 T101

O2 T151

ENTER MO. OF CHANMELS AT SITE

48

DATA IS BEIMG RETRIEUED

FIGURE 5. CHPLOT SCREEN DISPLAY 
FIGURE 6. DATA PLOT

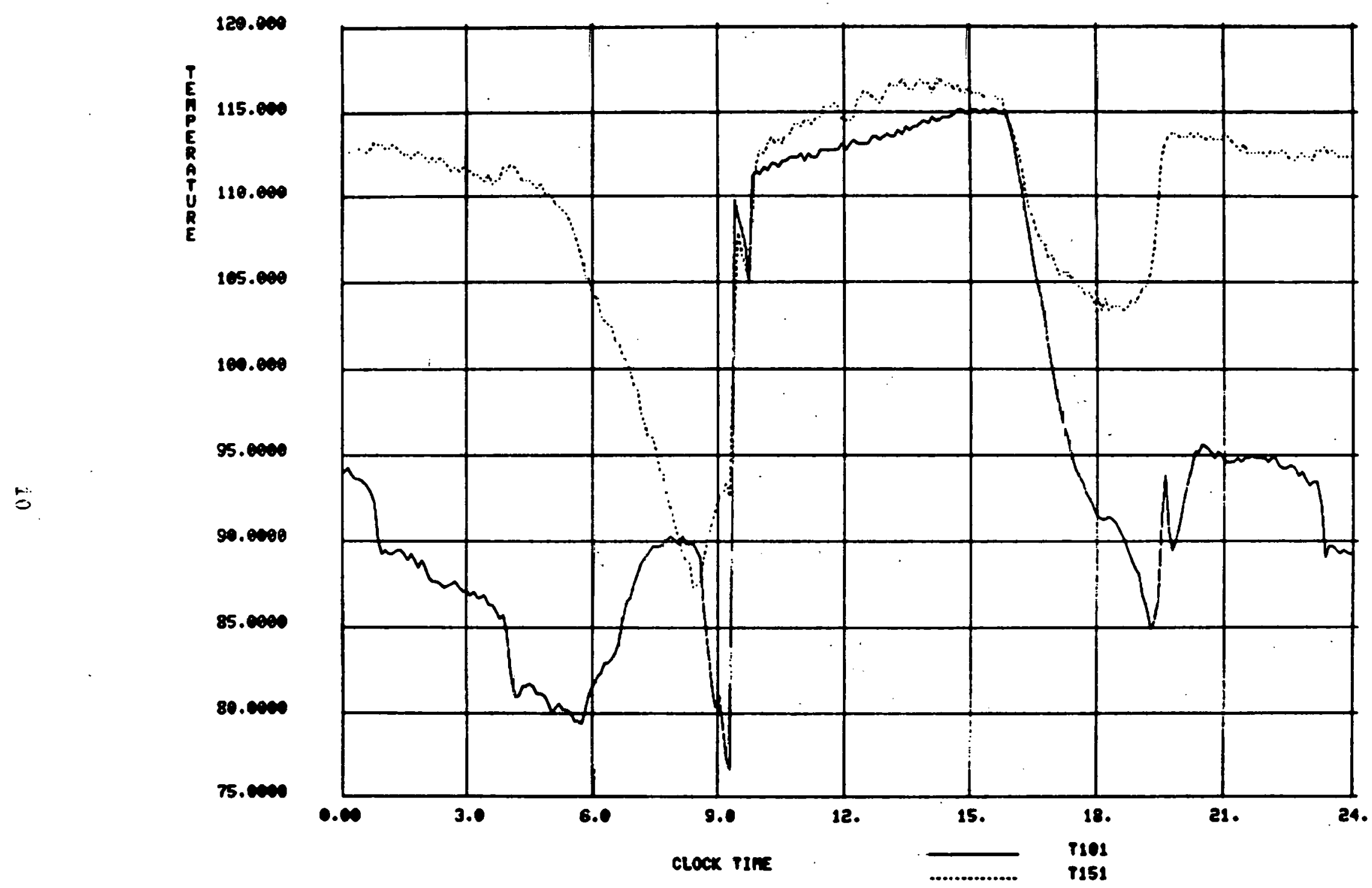

manese c/15m 


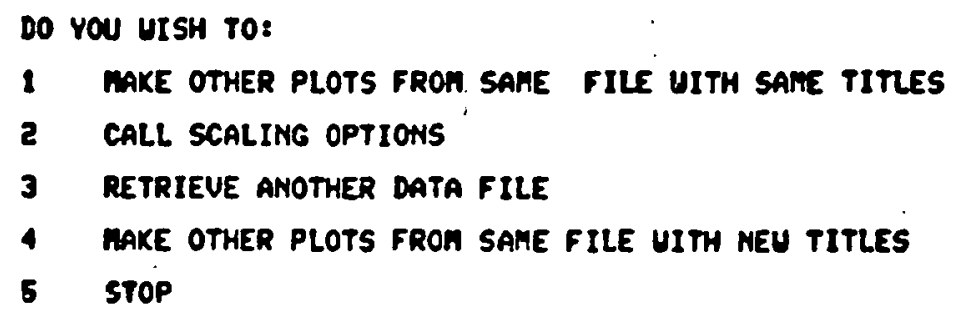

FIGURE 7. PLOTTING OPTIONS

DNTER MAXIMUM aND hIMIMUM VALUES FOR $X$ AND $Y$ Xhax. 22.

XIIN. O6.

max. 95.

MIN= 75.

FIGURE 8. SCALING OPTION DISPLAY - 
FIGURE 9. SCALED PIOT

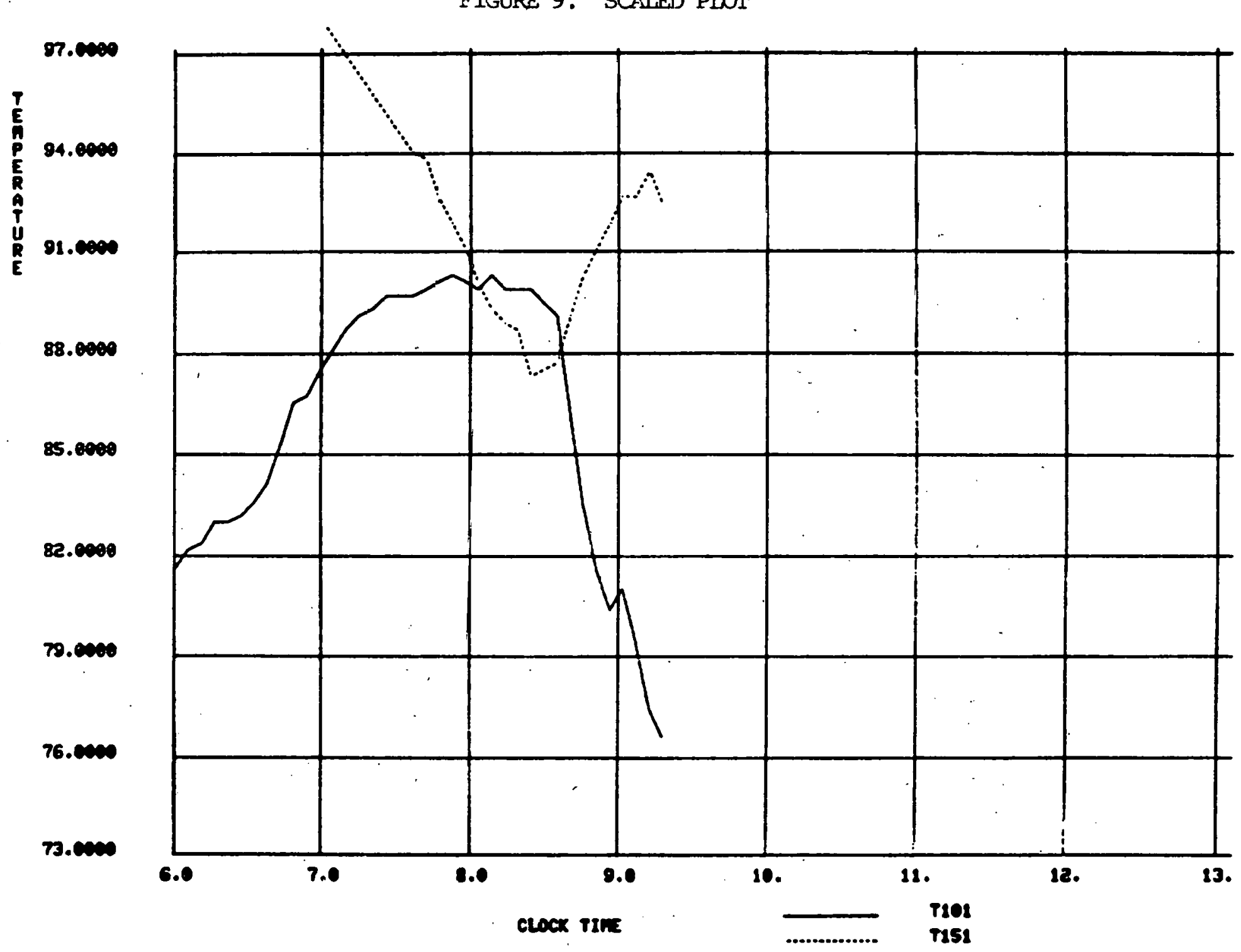

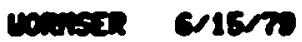




\section{WRTCNI. OPERATIONAL PROCEDURES}

The purpose of WRTCNL-is to tist-in a tabular form the data stored in a direct access unformatted file created by TAPFIL. The program has the capability to list the data for up to ten channels. Since WRTCNL does not contain any special routines, this program may be run from any terminal with the necessary capabilities.

The user inputs to this program are shown in Figure 10. The first input is the number of channels at the site. This is subject to the same restrictions specified in the description of TAPFIL. The next input is the number of channels to be output, with a maximum of ten. The third input is the channel numbers to be output. The IPCL should be referenced to obtain the correct channel numbers of the measurements desired. This is also the case for the next input, which is the measurement type and number. The last user input is the data file name of the stored data. This should be the name of a file created by TAPFIL.

After all inputs are completed, a listing of the requested data will be output to the line printer.

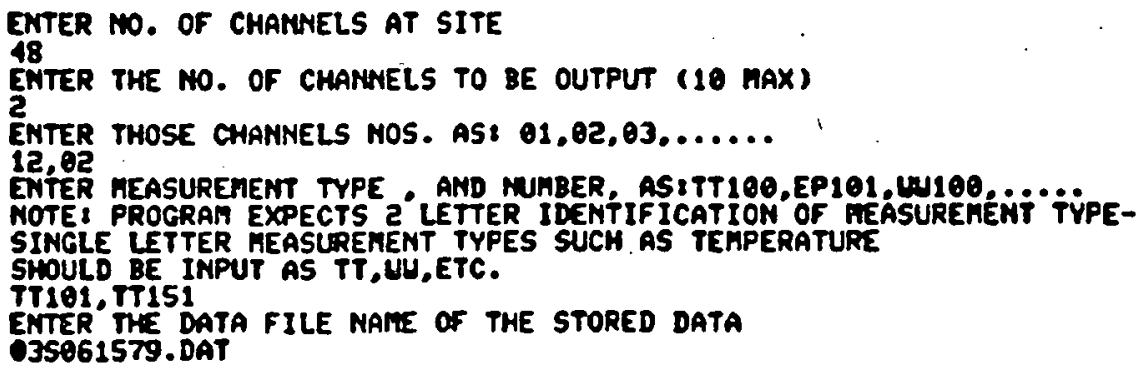

FIGURE 10. WRTCNL SCREEN DISPLAY 


\section{PROGRAM SOFTWARE IMPLEMENTATION}

The previously described programs were written for use on a PDP $11 / 70$ system with the 11-M operating version. Software capabilities of other computer systems could differ greatly; therefore, the software routines used in these programs.will be explained in dètail.

Three types of software routines are used by these programs - TEKPLOT Library routines, UTILITIES Library routines and Data Conversion routines. The first and largest set of routines used are the TEKPLOT routines. These routines are standard library software routines for the PDP 11/70. Libraries on other computer systems contain routines with different names that perform the same functions. Before these programs can be used on another computer, the TEKPLOT routines must be replaced by similar routines compatible to the computer used. The TEKPLOT routines are listed and described in Table 1.

The second type of sof tware routines are in the UTILITIES Library. There are four of these routines; three of these are tape handling routines and the fourth is a data conversion routine. Table 2 contains a liating and description of these routines.

Bytes 19-210 of a record are converted from EBCDIC floating point words to PDP $11 / 70$ words by a subroutine not included-in the UTILITIES Library. This routine 1s known as CFP360 and is used as CFP360(DAT(1),48,0). The first argument represents a real data array dimensioned large enough to contain 48 words. DAT(1) represents the starting position to perform the required conversion and the second argument represents the number of words to be converted. One byte of data on the IBM 360 tape is equivalent to one byte on the PDP $11 / 70$ and is represented by a LOGICAL*1 statement. On the PDP 11/70, one floating point word contains four bytes; therefore, 192 bytes of data are stored in the LOGICAL*1 data array from bytes 19-210. This indicates that 48 words are to be converted by the CFP360 routine. The last argument represents a byte-swap operation; a byte-swap is required for conversion from EBCDIC to PDP words, and is accomplished by setting the fourth argument to zero. The correlation hetween the LOGICAL*1 data array and the real data array used in CFP360 is done by an EQUIVALENCE statement. These statements are used:

$\begin{array}{ll}\text { DIMENSION } & \operatorname{DAT}(48) \\ \text { LOGICAL } 1 & \text { DATA }(210) \\ \text { EQUIVALENCE } & (\operatorname{DATA}(19), \operatorname{DAT}(1))\end{array}$

This will equivalence the real dimensioned array DAT to the last 192 bytes of the LOGICAL* 1 array DATA so that CFP360 can convert real data words.

The tape handling routines are standard software routines and can easily be compared to routines on another computer with a tape drive, but the two data conversion routines, EBCASC and CFP360, were developed for the MSFC PDP 11/70. Therefore, the comparable conversion routine to be used on another computer would need to convert EBCDIC characters to compatible characters for that computer system. Once the use of the above routines is understood, any experienced programmer should be able to implement these programs on any computer using FORTRAN IV PLUS. 
TABLE 1

TEKPLOT ROUTINES

ALPHA-

Places terminal in alphanumeric mode, cursor at current $(x, y)$ position. AXIS (XLOW, YLOW, XLNG , YLNG , XTIC, YTIC , MARKX, MARKY) -

Draws $X$ and $Y$ axes. Each line must pass through the origin. If not,

"the routine returns with no action. After the axes are drawn, the user is left in vector mode positioned at the origin.

XLOW- starting position on $X$ axis in scaled, rotated units. Must be the lowest point through which the $\mathrm{X}$ axis will pass.

YLOW- equivalent of XLOW pertaining to the $Y$ axis.

XLNG- length of $X$ axis in scaled units

YLNG- length of $Y$ axis in scaled units

XTIC- distance between tic marks on X axis. If XTIC is negative, then is the distance between decades for a $\log$ axis.

YTIC- equivalent of XTIC pertaining to $Y$ axis

MARKX- $=0$, no axis annotation for $X$ axis .GT. 0 , tic mark annotation for $\mathrm{X}$ axis

.LT. 0 , grid annotation for $\mathrm{X}$ axis

MARKY- equivalent of MARKX pertaining to the $Y$ axis.

$\operatorname{BEGIN}(J B A U D)-$

Initializes the terminal status area and the software character generator. Should always be the first subroutine called in any program.

JBAUD- the baud rate of the current installation.

$\operatorname{CHOUT}(\mathrm{J})-$

Outputs a single character.

J- ASCII value of a character to be output to the T4014 scope

ERASE-

Erases the screen, places the terminal in alphanumeric mode, positions cursor to home position.

HOME-

Positions cursor to the upper left corner of the screen POINT-

Places terminal in point plot mode and positions cursor to the current graphics position. 
SCALE (XFACT, YFACT, XORG, YORG) -

Establishes $X$ and $Y$ scaling factors and $X$ and $Y$ origin

XFACT- X scaling factor (=tekpoints/scaled unit)

YFACT- Y scaling factor (=tekpoints/scaled unit)

XORG- $\mathrm{X}$ origin in tekpoints

YORG- Y origin in tekpoints

TPAUSE-

Causes a user to become $I / O$ bound for an indefinite period of time. This allows the user to sit and wait while inspecting a plot without incurring CPU charges when working in a time sharing envi ronment.

$\operatorname{TPLOT}(\mathrm{X}, \mathrm{Y}$, IPEN, MARK) -

Plots an $(x, y)$ coordinate in the current mode.

$X-X$ value in scaled, rotated points

$\mathrm{Y}-\mathrm{Y}$ value in scaled rotated points

IPEN- $=0$, dark plot (pen up)

.NE. 0, bright plot (pen down)

MARK- the number of a data mark from the following list:

0 - no data mark

$1-\operatorname{small} x$

2- small down arrow

3- small up arrow

4- small square

5- small triangle

6- small asterick

11- large $x$

12- large down arrow

13- large up arrow

14- large square

15- large triangle

16- large asterick

VECTOR-

Draws a smooth line between the current graphics position and the $(x, y)$

point specified as a parameter to any of the plotting routines. 
UTILITIES ROUTINES

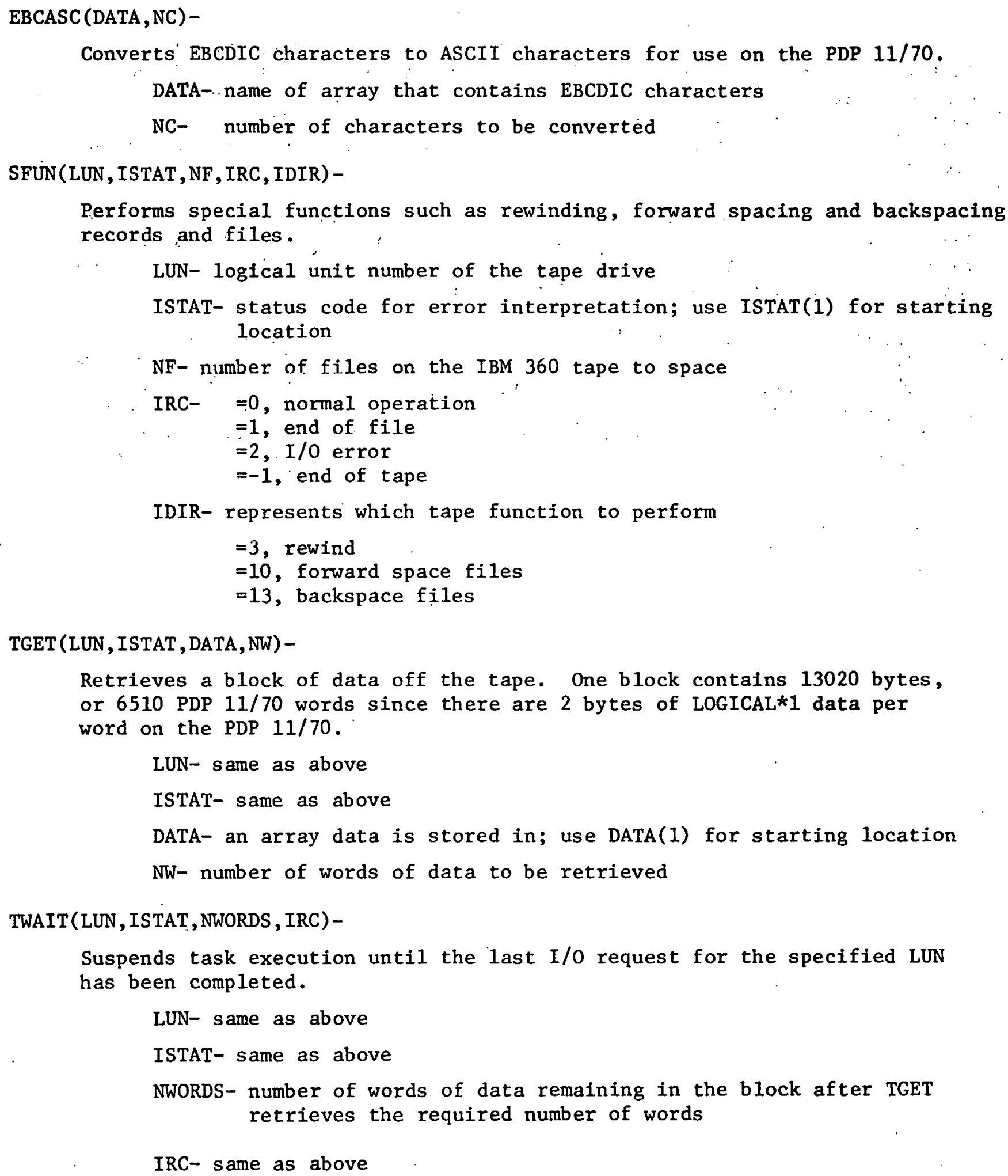


Of the three programs previously described, the understanding of TAPFIL is the most essential. CHPLOT and WRTCNL cannot be run until TAPFIL has created a direct access unformatted file from the data tape. Several other programs which require the use of TAPFIL to retrieve the data are currently in use at MSFC. These programs perform various analyses pertaining to collector efficiency.

CHPLOT can be used to plot daily data, thus enabling the user to find a day which appears to have usable data. WK'LNL can be used if a listing of thio data is desired. After a good day has been found using CHPLOT, the data can then be used in the analysis of collector efficiency.

Another program currenty in the development stage at MSFC will allow monthly data to be plotted without the prior use of TAPFIL. This program will read the data straight from the IBM tape and plot it one week at a time. The advantage of this program will be that the user can find good days without using TAPFIL to create numerous individual files. After the good days have been located, TAPFIL can then be used to create only the necessary files. 
APPENDIX A

SAMPLE PROBLEM 
TAPE TO FILE PROGRAM

SYSTENS REOUIREMENTS BRANCH

SYSTEMS ANALYSIS AND INTEGRATION LABORATORY

EMTER THE MUESR OF CHAWHELS AT SITE

48

ENTER DESIRED DATE OF DATA TO BE RETRIEUED ASI MO DA YR

61579

ENTER DATA FILE NAME

O3SOG1579.DAT

ENTER THE FILE NUABER OF THE DATA DATE

16

DO YOU UANT A LIKE PRINTER TINE PROFILE? (1-YES, 2-NO)

DATA IS MOU BEIMG RETRIEUED 
TPFIL TIME PROFILE

\begin{tabular}{|c|c|c|c|c|c|c|c|c|c|c|c|}
\hline $\begin{array}{l}86 / 15 \\
06 / 15 \\
06 / 15 \\
06 / 15 \\
06 / 15 \\
06 / 15 \\
06 / 15 \\
06 / 15 \\
06 / 15 \\
06 / 15 \\
06 / 15 \\
06 / 15 \\
06 / 15 \\
06 / 15 \\
06 / 15 \\
06 / 15 \\
06 / 15 \\
06 / 15 \\
06 / 15 \\
06 / 15 \\
06 / 15 \\
06 / 15 \\
06 / 15 \\
06 / 15 \\
06 / 15 \\
06 / 15 \\
06 / 15 \\
06 / 15 \\
06 / 15 \\
06 / 15 \\
06 / 15 \\
06 / 15 \\
06 / 15 \\
06 / 15 \\
06 / 15 \\
06 / 15 \\
06 / 15 \\
06 / 15 \\
06 / 15 \\
06 / 15 \\
06 / 15 \\
06 / 15 \\
06 / 15\end{array}$ & 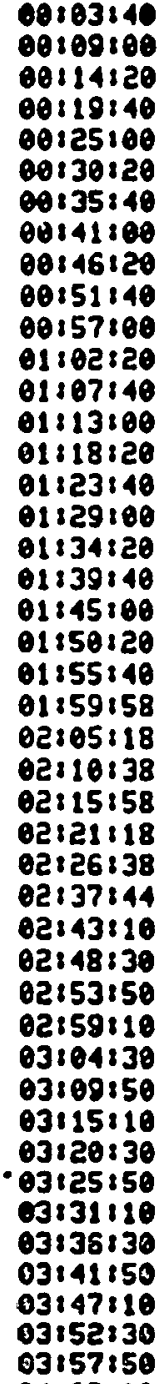 & 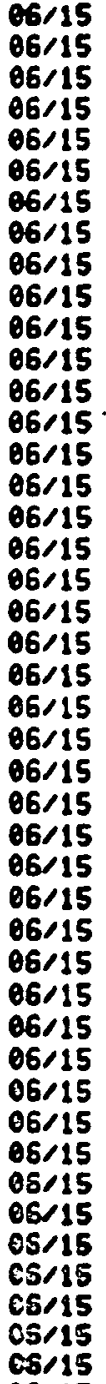 & 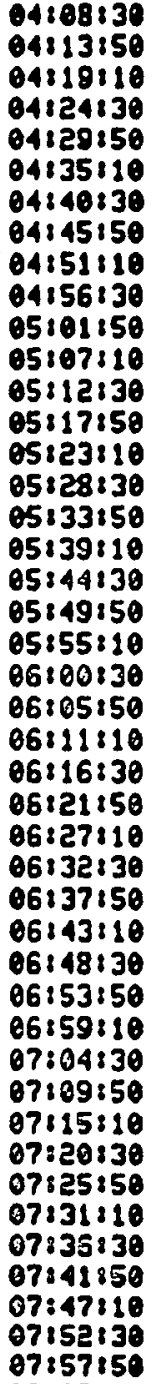 & $\begin{array}{l}06 / 15 \\
06 / 15 \\
06 / 15 \\
06 / 15 \\
06 / 15 \\
06 / 15 \\
06 / 15 \\
66 / 15 \\
06 / 15 \\
06 / 15 \\
06 / 15 \\
06 / 15 \\
06 / 15 \\
06 / 15 \\
06 / 15 \\
06 / 15 \\
06 / 15 \\
06 / 15 \\
06 / 15 \\
06 / 15 \\
06 / 15 \\
06 / 15 \\
06 / 15 \\
06 / 15 \\
06 / 15 \\
06 / 15 \\
06 / 15 \\
66 / 15 \\
06 / 15 \\
06 / 15 \\
06 / 15 \\
06 / 15 \\
06 / 15 \\
06 / 15 \\
06 / 15 \\
06 / 15 \\
06 / 15 \\
65 / 15 \\
66 / 15 \\
06 / 15 \\
65 / 15 \\
06 / 15 \\
\theta 6 / 15\end{array}$ & 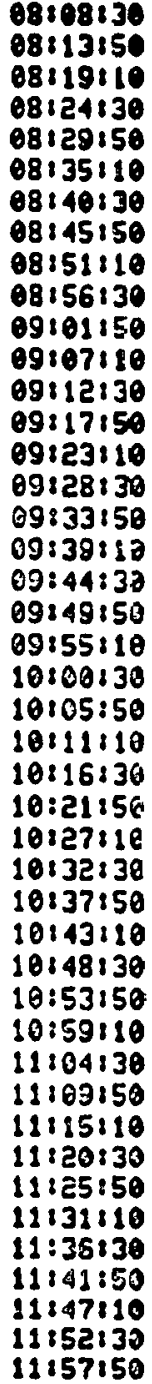 & $\begin{array}{l}06 / 15 \\
06 / 15 \\
06 / 15 \\
06 / 15 \\
06 / 15 \\
06 / 15 \\
06 / 15 \\
06 / 15 \\
06 / 15 \\
06 / 15 \\
06 / 15 \\
06 / 115 \\
06 / 15 \\
06 / 15 \\
06 / 15 \\
06 / 15 \\
06 / 15 \\
05 / 15 \\
66 / 15 \\
05 / 15 \\
06 / 15 \\
06 / 115 \\
06 / 15 \\
06 / 15 \\
05 / 15 \\
06 / 15 \\
06 / 15 \\
06 / 15 \\
06 / 15 \\
06 / 15 \\
06 / 15 \\
05 / 15 \\
05 / 15 \\
05 / 15 \\
06 / 15 \\
05 / 15 \\
05 / 15 \\
05 / 15 \\
05 / 15 \\
05 / 15 \\
05 / 15 \\
05 / 15\end{array}$ & 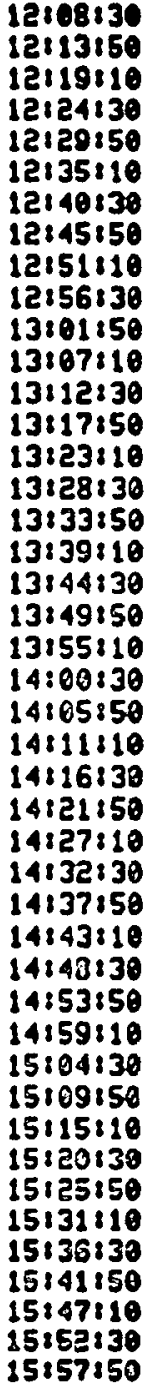 & $\begin{array}{l}06 / 15 \\
06 / 15 \\
06 / 15 \\
06 / 15 \\
06 / 15 \\
06 / 15 \\
06 / 15 \\
06 / 15 \\
06 / 15 \\
06 / 15 \\
06 / 15 \\
06 / 15 \\
06 / 15 \\
06 / 15 \\
06 / 15 \\
06 / 15 \\
05 / 15 \\
06 / 15 \\
06 / 15 \\
06 / 15 \\
06 / 15 \\
06 / 15 \\
06 / 15 \\
06 / 15 \\
06 / 115 \\
06 / 15 \\
06 / 15 \\
06 / 15 \\
06 / 15 \\
06 / 15 \\
06 / 15 \\
66 / 15 \\
05 / 15 \\
06 / 15 \\
05 / 15 \\
06 / 15 \\
06 / 15 \\
05 / 15 \\
06 / 15 \\
05 / 15 \\
05 / 15 \\
05 / 15 \\
66 / 15 \\
65 / 15\end{array}$ & 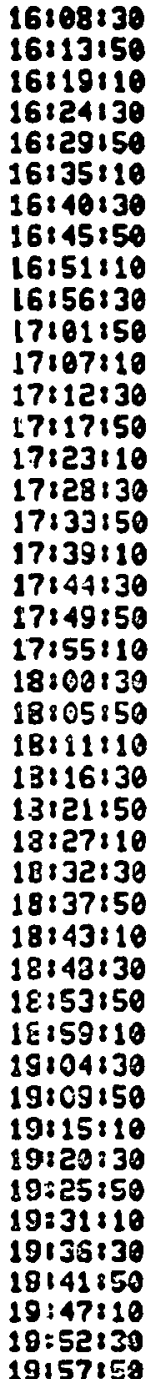 & $\begin{array}{l}06 / 15 \\
06 / 15 \\
06 / 15 \\
06 / 15 \\
06 / 15 \\
06 / 15 \\
06 / 15 \\
06 / 15 \\
06 / 15 \\
06 / 15 \\
06 / 15 \\
06 / 15 \\
06 / 15 \\
06 / 15 \\
06 / 15 \\
06 / 15 \\
06 / 15 \\
06 / 15 \\
06 / 115 \\
06 / 15 \\
06 / 15 \\
06 / 15 \\
06 / 15 \\
06 / 115 \\
06 / 15 \\
06 / 15 \\
06 / 15 \\
06 / 15 \\
06 / 15 \\
06 / 15 \\
06 / 15 \\
06 / 15 \\
06 / 15 \\
06 / 15 \\
06 / 15 \\
06 / 15 \\
06 / 15 \\
06 / 15 \\
66 / 15 \\
06 / 15 \\
05 / 15 \\
06 / 15 \\
06 / 15 \\
06 / 15\end{array}$ & $\begin{array}{l}2010813 \\
2011315\end{array}$ \\
\hline
\end{tabular}

$06 / 15$ 04103110 es/15 08103i10 06/15 12103110 C5/15 16103110 c5/15 20:03i10

THE DATA HAS DEEA STORED UITH 260 RECORDS 


\section{EL 55 Chammel Plotting progran}

ENTER PLOT FILE MANE

035061579.DAT

ENTER NO. OF PLOTS ON THIS GRAPH (MAX.5)

2

ENTER PLOT CAPTION (A9 CMARACTERS)

LORASER 6/15/79

ENTER CAPTION FOR LEFT SIDE OF PLOT

TEMPERATURE

ENTER CHANELL NO. AND UNITS

12 T101

02 T15\&

ENTER NO. OF CHAMELS AT SITE

48

DATA IS BEIMG RETRIEUED 


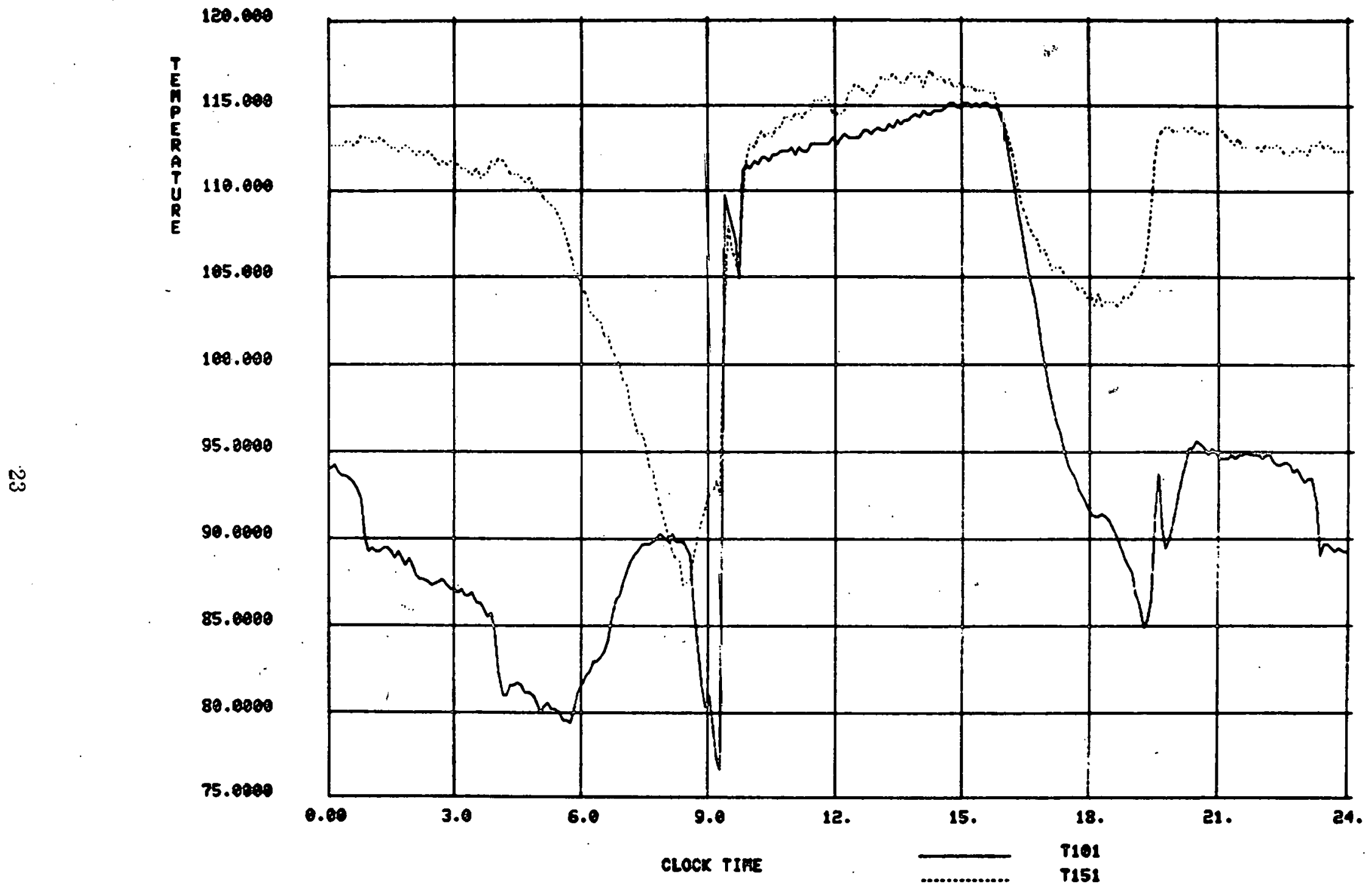

HOAREER 6/15/70 
DO YOW UISH TOS

1 Maxe OTHER PLOTS FRON SAME FILE UITH SANE TITLES

2 Call SCALING OPTIONS

3 RETRIEUE AWOTIER DATA FILE

4 Maxe OTHER PLOTS FROA SANE FILE UITH KEd TITLES 
WRTCNL PROGRAM

\section{EMTER MO. OF CHAMEELS AT SITE \\ EMTER THE NO. OF CHAAMELS TO BE OUTPUT (10 RAX) \\ EMTER THOSE CHANGels nOS. AS: $01,02,03, \ldots .$. .

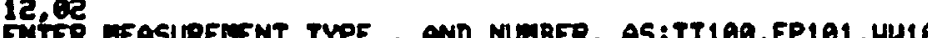 \\ WOTE: PROGRAH EXPECTS 2 ' LETTER IDEMTIFICATION OF MEASUREMENTT' TYPE- \\ SIMGLE LETTER TEASUREMEMT TVPES SUCH AS TEMPERATURE \\ SHOULD BE INPUT AS TT,W,ETC. \\ Tr101. Tr151 \\ THIOR. THE DATA FILE MAME OF THE STORED DATA
O3SEO1579. DAT}




\begin{tabular}{|c|c|c|}
\hline 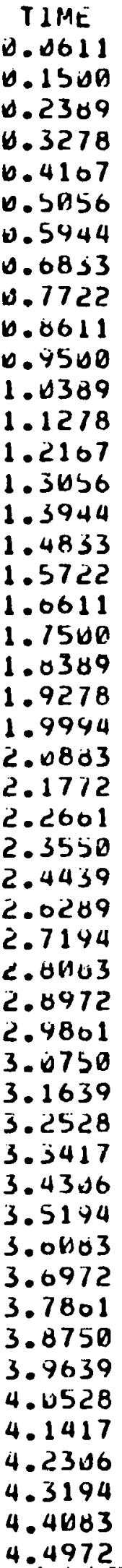 & 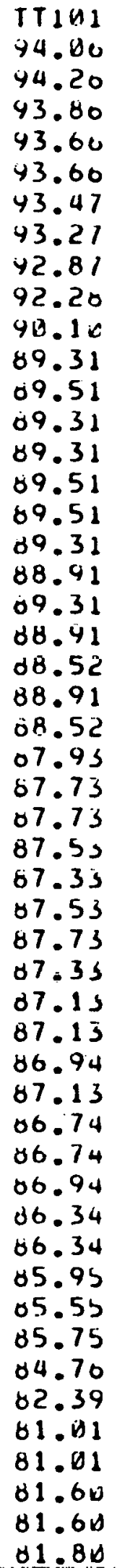 & $\begin{array}{l}17151 \\
112.70 \\
112.70 \\
112.70 \\
112.71 \\
112.90 \\
112.90 \\
112.71 \\
112.40 \\
113.30 \\
113.10 \\
113.10 \\
112.40 \\
112.901 \\
113.10 \\
112.90 \\
112.70 \\
112.50 \\
112.50 \\
112.30 \\
112.50 \\
112.70 \\
112.50 \\
112.30 \\
112.10 \\
112.36 \\
112.10 \\
112.30 \\
112.10 \\
111.51 \\
111.71 \\
111.31 \\
111.71 \\
111.71 \\
111.51 \\
111.31 \\
111.31 \\
1111.11 \\
1110.41 \\
111.31 \\
1110.71 \\
1110.91 \\
111.11 \\
111.71 \\
111.51 \\
111.90 \\
111.71 \\
111.31 \\
1110.91 \\
1110.91 \\
110.91\end{array}$ \\
\hline
\end{tabular}

This is a sample of the printout produced by WRTCNL. 
APPENDIX B

FLOWCHARTS and REFERENCE TABLES 


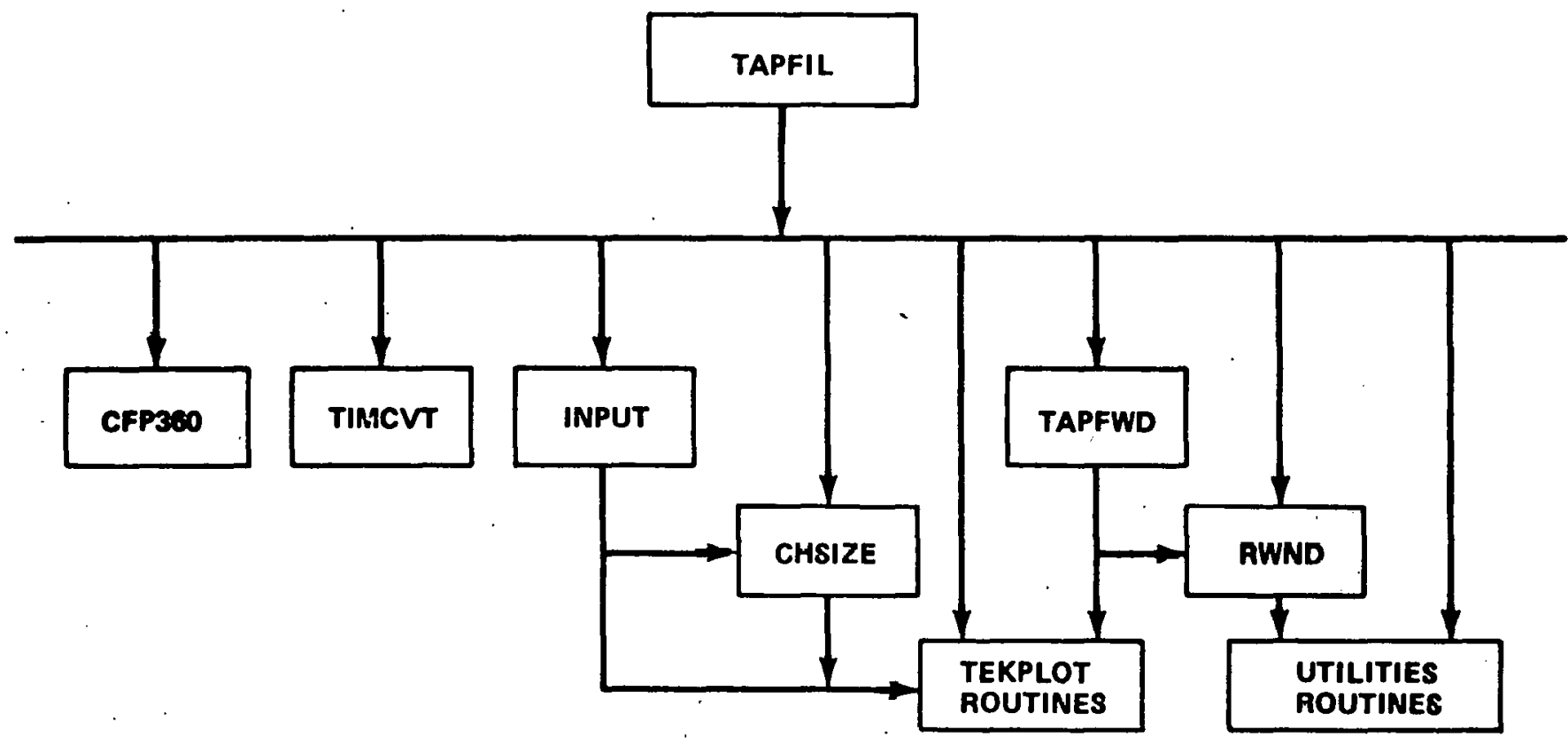

TAPFIL FLOWCHART

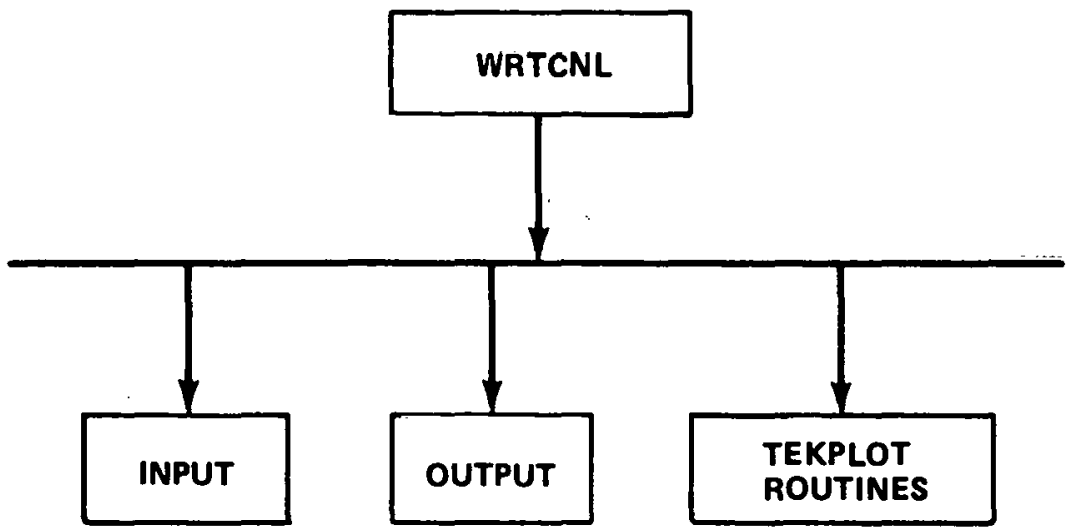

WRTCNL FLOWCHART 


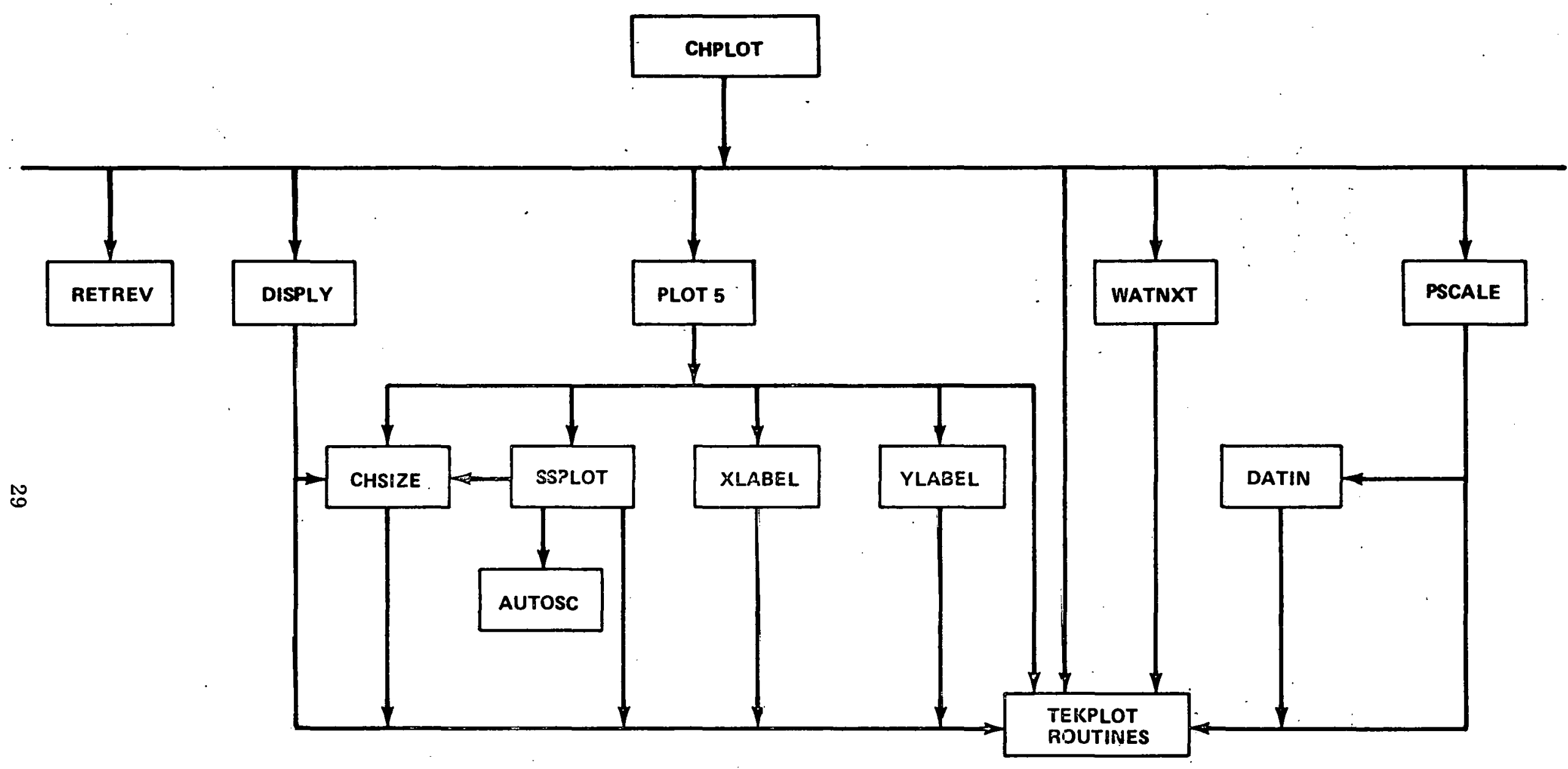

CHPLOT FLONCHART 


\begin{abstract}
CFP360- converts EBCDIC floating point words to PDP $11 / 70$ words CHSIZE- changes character size on a TEKTRONIX 4014 display scope INPUT- $\quad$ reads user inputs regarding site data imformation RWND- $\quad$ rewinds tape

\title{
CHPLOT SUBROUTINE LIST
}

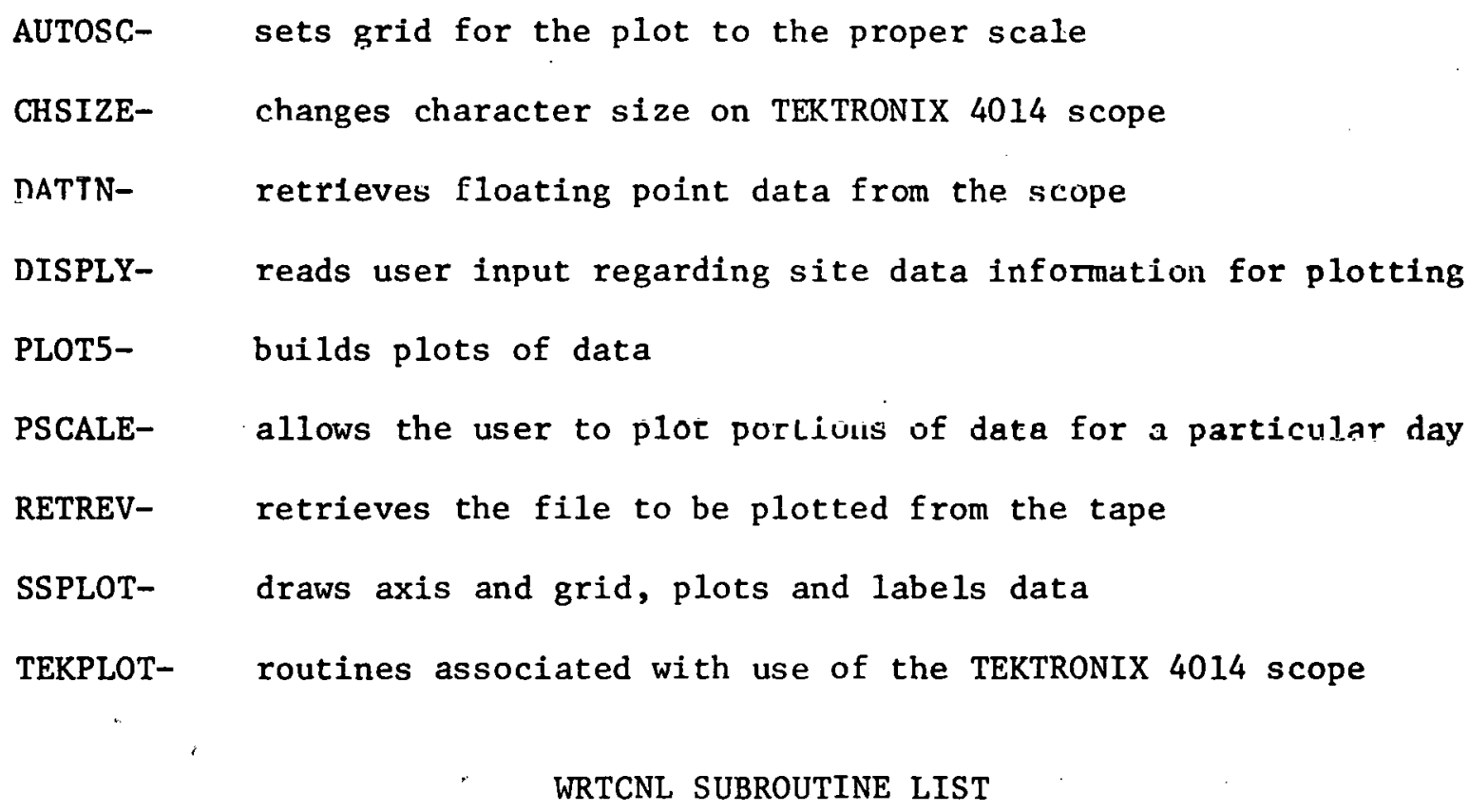


APPENDIX C

TAPFIL SOURCE LISTING 


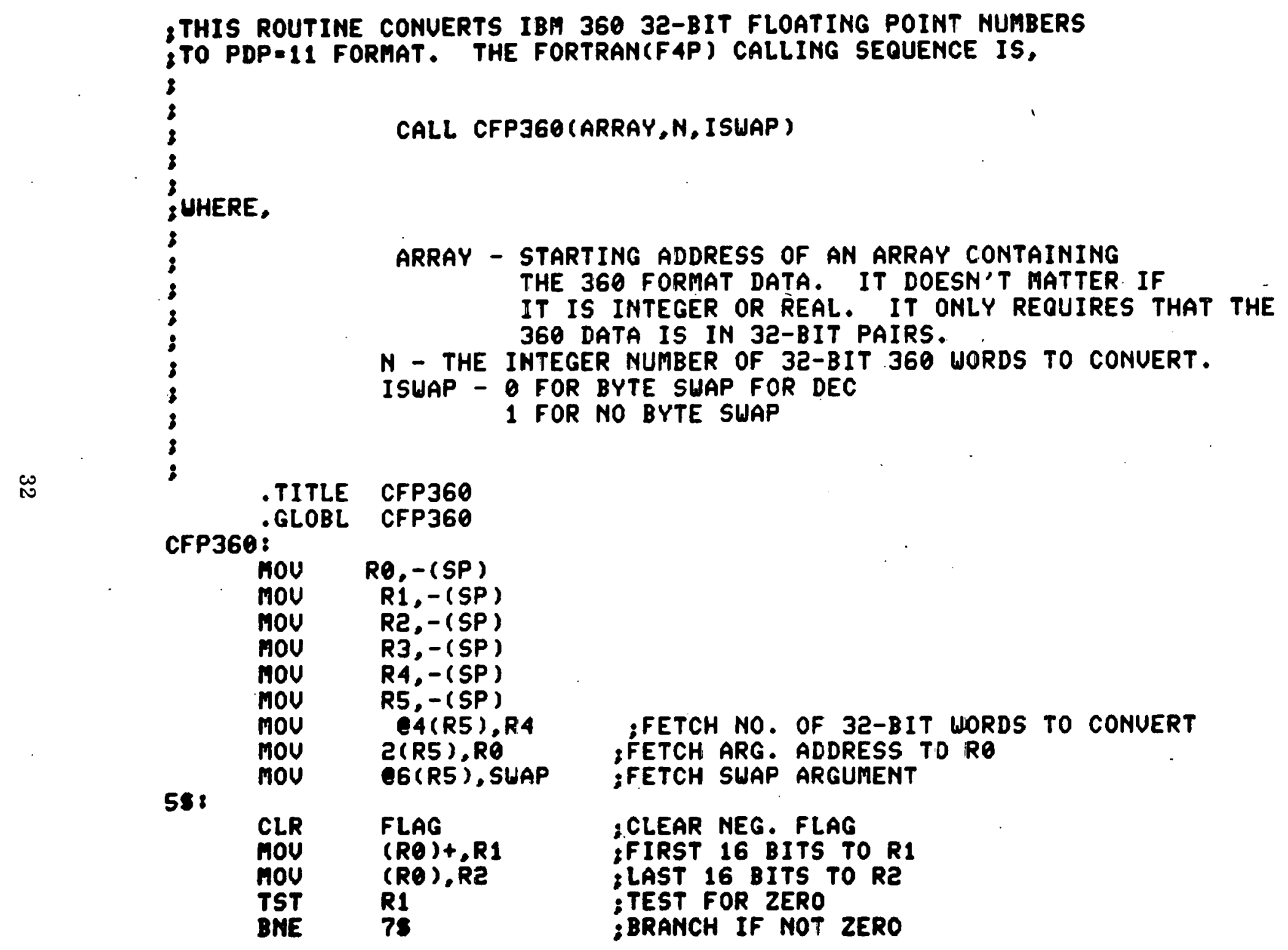




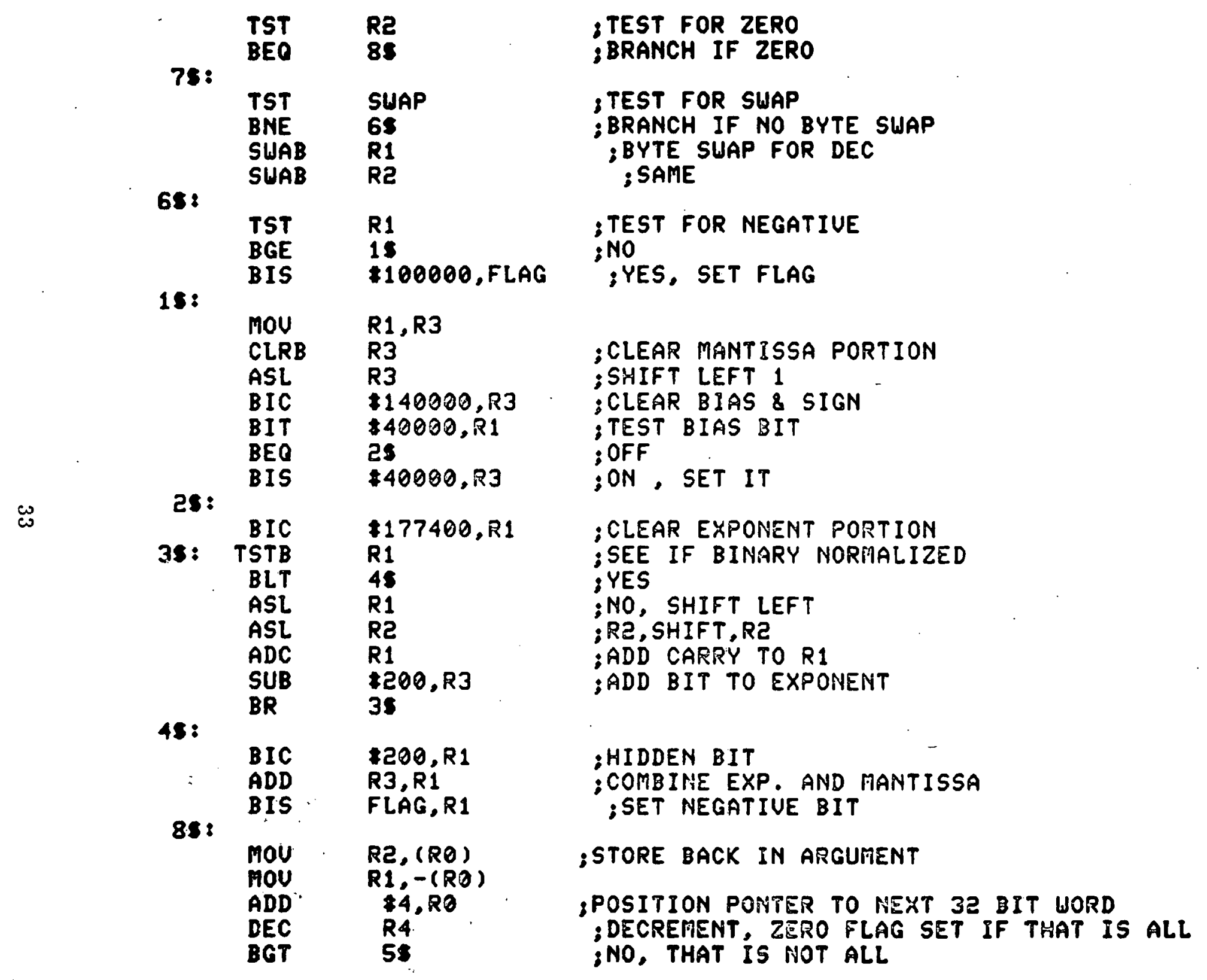




\begin{tabular}{|c|c|c|}
\hline & $\begin{array}{l}\text { MOU } \\
\text { MOU } \\
\text { MOU } \\
\text { MOU } \\
\text { MOU } \\
\text { MOU } \\
\text { RTS } \\
\text {. WORD }\end{array}$ & $\begin{array}{l}(S P)+, R S \\
(S P)+, R 4 \\
(S P)+, R 3 \\
(S P)+, R 2 \\
(S P)+, R 1 \\
(S P)+. R \theta \\
P C \\
0\end{array}$ \\
\hline & $\begin{array}{l}\text { - WORD } \\
\text {.END }\end{array}$ & 0 \\
\hline
\end{tabular}


SUBROUTIME CHSIZE(N)

CXXX THIS ROUTINE CHANGES CHARACTER SIZE ON A TEKTRONIX 4014-1 DISPLAY

CXXX SCOPE ACCORDING TO $N$ AS FOLLOUS: $N=1$ - LARGEST

Cxts

Cx*s:

$N=2$ - NEXT SMALLER

$N=3$ - NEXT SMALLER

Cxxt

$\mathrm{NP}=\mathrm{N}+55$

$N=4$ - SMALLEST

CALL CHOUT (27)

CALL CHOUT (NP)

RETURN

END 
SUBROUTINE INPUT (NCH, NF ILE, ILP, IREP)

LOGICALX1 IFILE (30), IDATE (6)

CORMON/FILE/IFILE

COMMON/DATE/IDATE

COMMON/UHERE /XS, YS

$Y S=730$.

$X S=50$.

CALL ALPHA

LUN $=$ ?

IF (IREP.EQ.1) GO TO 22

CALL CHSIZE(2)

CALL TPLOT (XS,YS, 0,0$)$

URITE $(1,5)$

5 FORMAT (1H+, 'TAPE TO FILE PROGRAM')

YS $=$ YS - 25.

CALL TPLOT $(X S, Y S, 0,0)$

URITE $(1,6)$

FORMAT (1H+,'SYSTEMS REOUIREMENTS BRANCH')

$Y S=Y S-25$.

CALL TPLOT(XS,YS, 0,0$)$

WRITE $(1,8)$

8 FORMAT (IH+, 'SYSTEMS ANALYSIS AND INTEGRATION LABORATORY')

YS =YS - 30

CALL CHSIZE( 3 )

CALL TPLOT $(X S, Y 5,0,0)$

URITE (1,15)

15 FORMAT(1H+, 'ENTER THE NUMBER OF CHANNELS AT SITE')

$Y S=Y S-15$

CALL TPLOT (XS,YS,O,D)

20

READ (1.20) $\mathrm{NCH}$

FORMAT (I 4 )

YS-YS-15.

22 CALL TPLOT(XS,YS, 0,0$)$

WRITE (1.25)

25 FORMAT (IH+, 'ENTER DESIRED DATE OF DATA TO BE RETREIUED

* AS\& MO DA YR'?

$Y S=Y S-15$. 


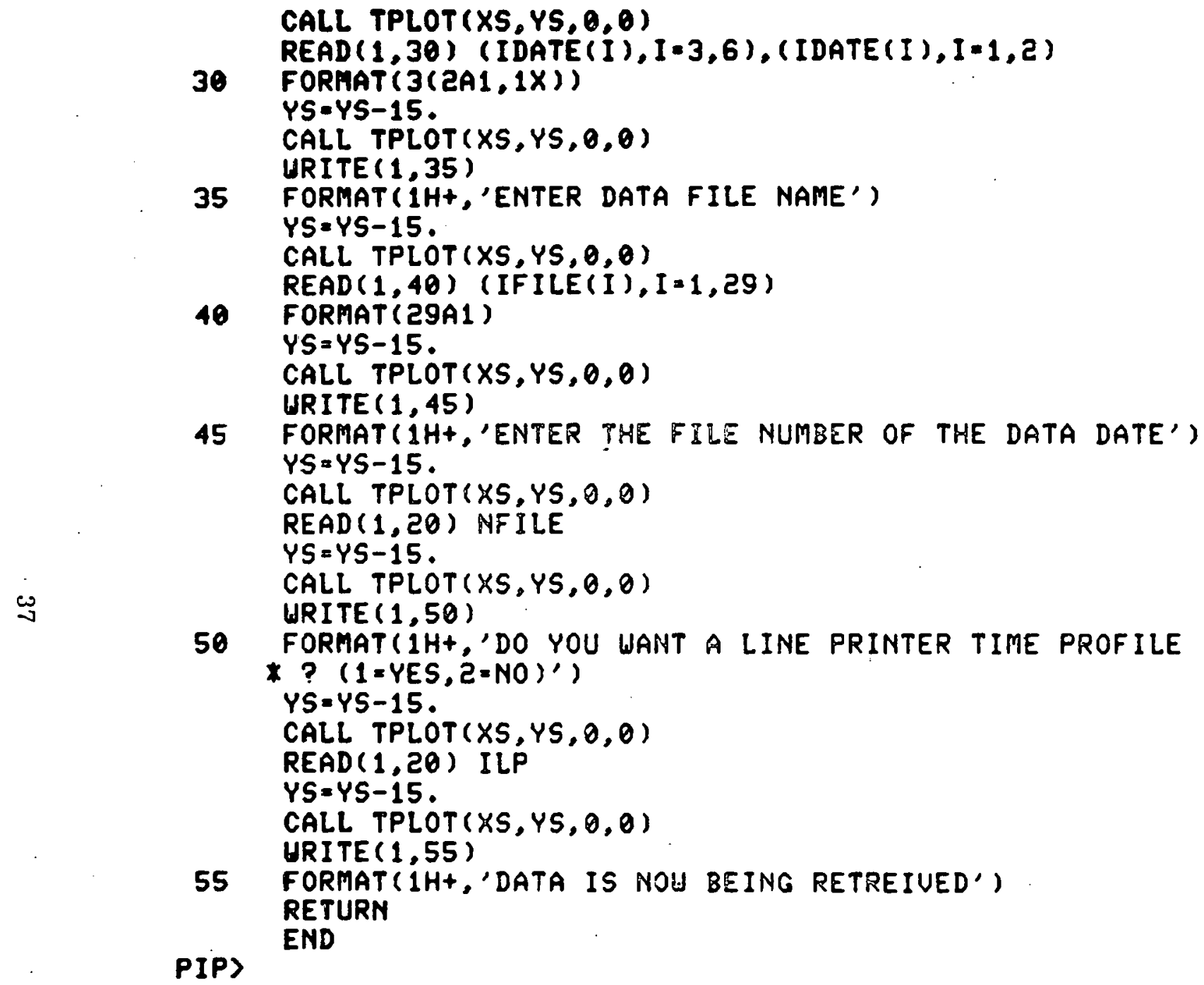


SUBROUTINE RUND(ISTAT)

DIMENSION ISTAT (1)

LUN=?

CALL SFUN(LUN, ISTAT, IDAT, IRC, 3)

CALL TUAIT (LUN, ISTAT, NUORDS, IRC)

RETURN

PIPP

END 
TAPFIL:

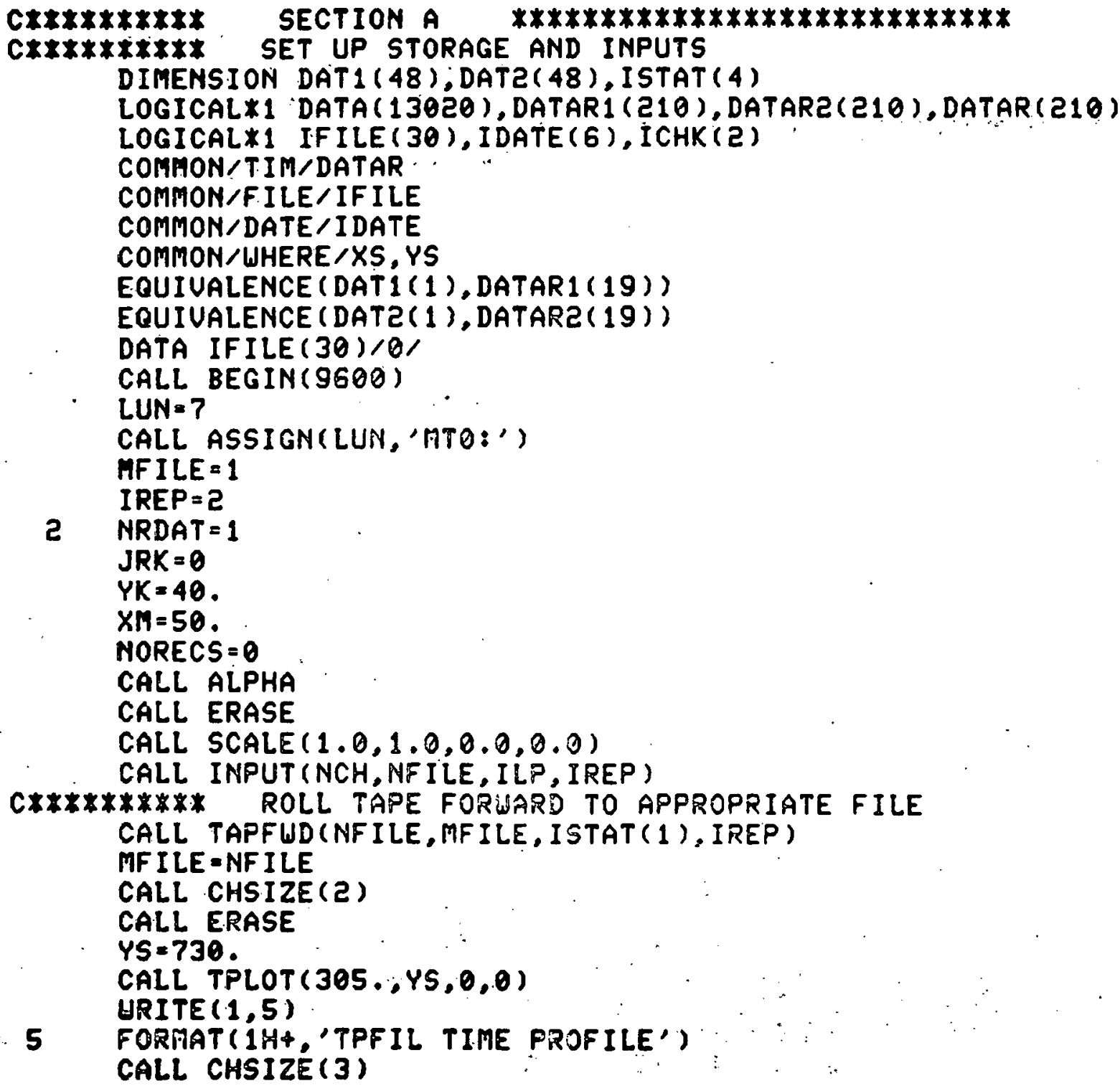




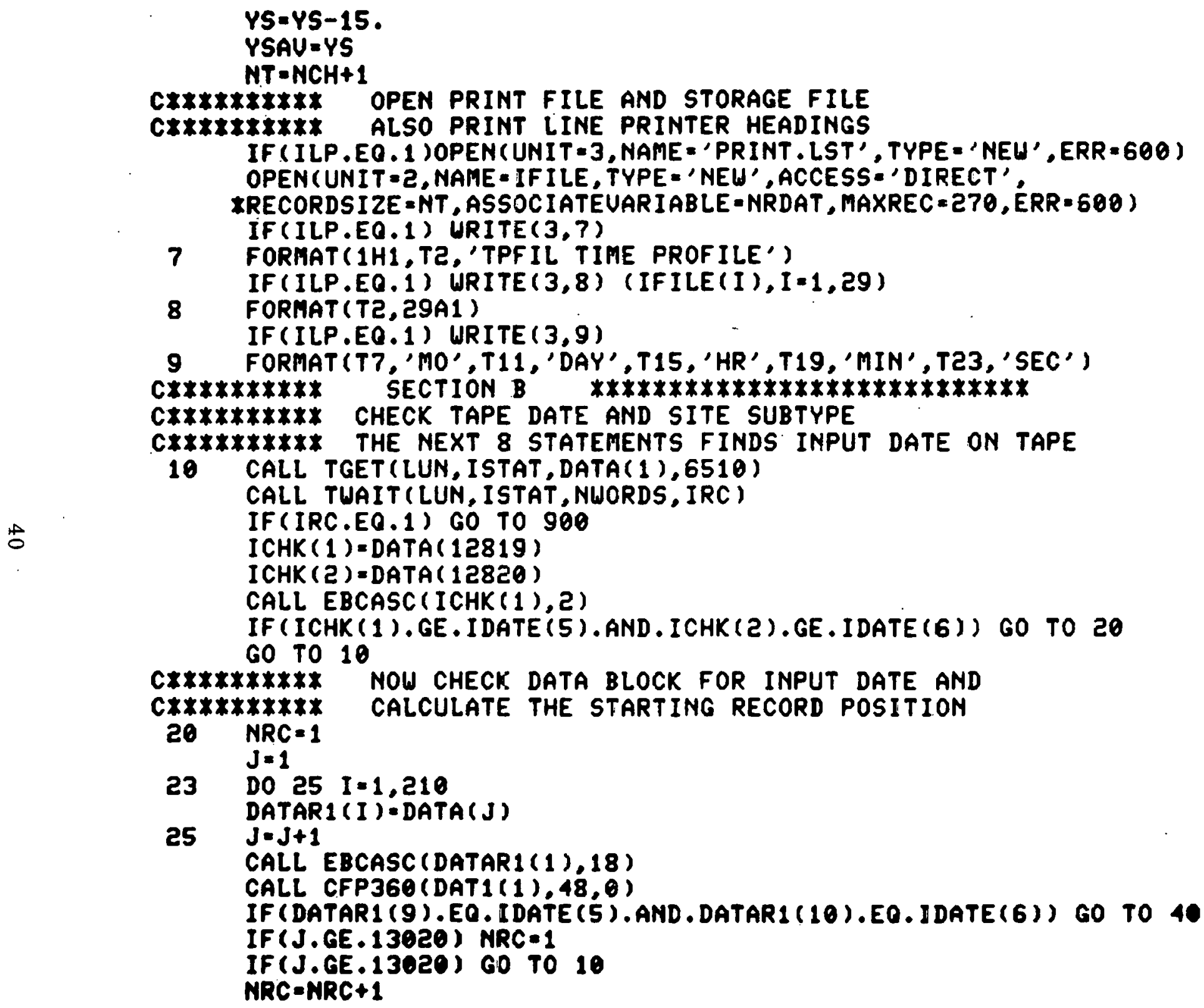









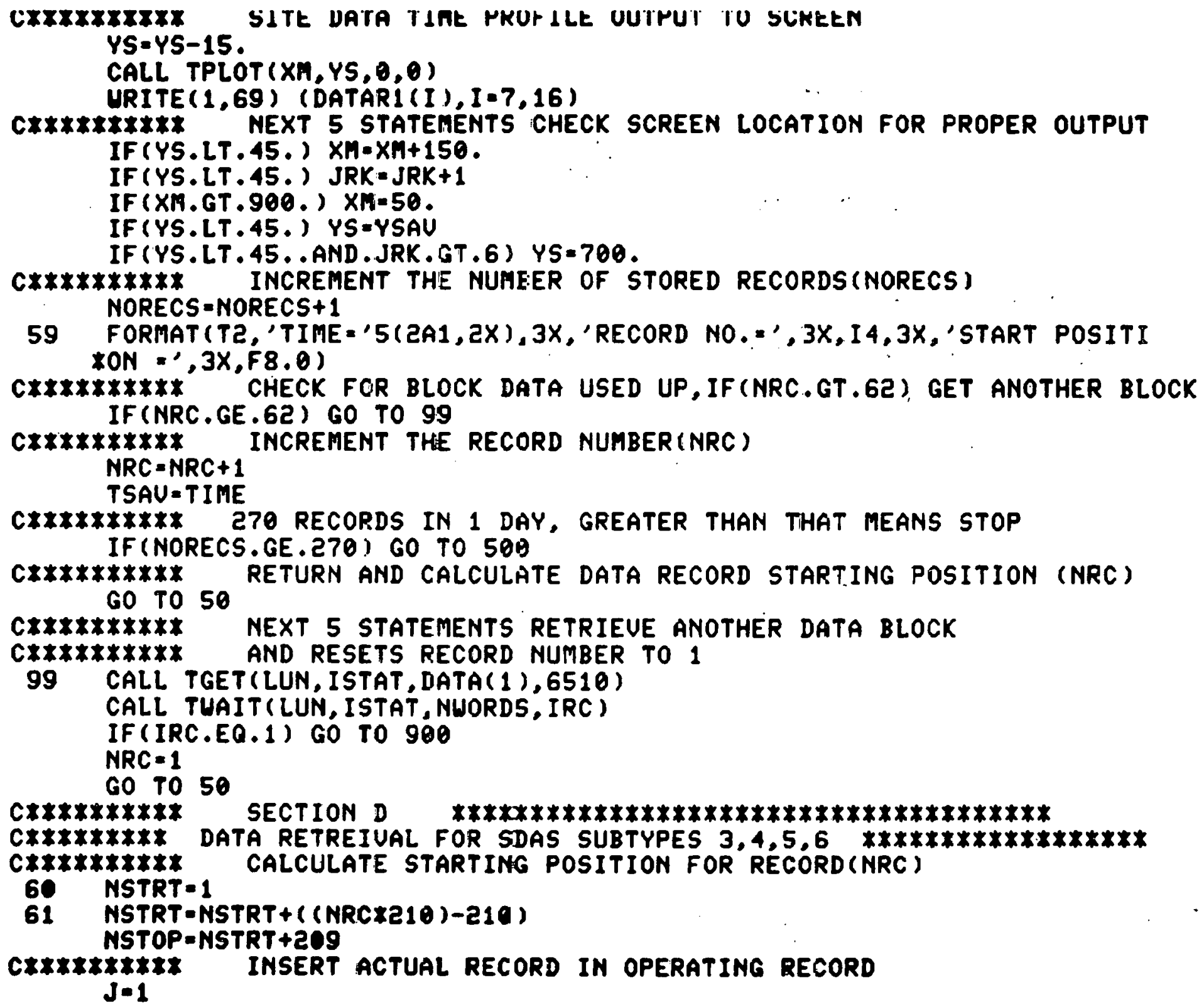


DO 65 I=NSTRT, NSTOP

DATARI (J)=DATA (I)

65 $\operatorname{IF}(I . L T .12811)$ DATAR2 $(J)=\operatorname{DATA}(I+21 \theta)$

$65 \mathrm{~J}=\mathrm{J}+1$

$\mathrm{s}$ CONUERT OPERATING RECORD FROM EBCDIC CHARACTERS TO ASCII CHARACTER

CALL EBCASC(DATARI(1),18)

IF (NSTRT.LT.12811) CALL EBCASC (DATARZ (1),18)

C**********. CONUERT EBCDIC DATA WORDS TO PDP WORDS

CALL CFP360(DAT1(1),48,0)

IF (NSTRT.LT.12811) CALL CFP360(DAT2(1),48,0)

IF (NSTRT.GE.12811) GO TO 90

C********** CHECK FOR CONTIGUOUS FECORDS

IF(DATAR1(17).EQ.DATARE\{ 37$\})$, 307075

C********** CHECK DATE ON TAPE AGAINSTT INPUT DATE

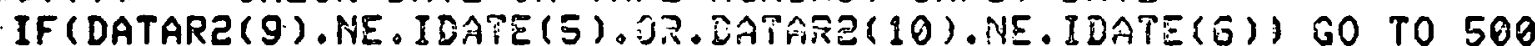

IF (DATAR1 (17). EO.53) GO TO 30

C***X****** INSERT DATARI IN DATAR FOR USE UITH TIAE CONLERSION(TIMCUT)

Do $66 \quad I=1,18$

$66 \operatorname{DATAR}(I)=$ DATARI (I)

C********** CONUERT TIHE FROA ASCII CHARACTERS TO DECIMAL EOUIUALENT CALL TIMCUT (TIME1)

C********** INSERT DATAR2 IN DATAR FOR USE UITH TIME CONUERSION(TIMCUT) DO $67 I=1,18$

67 DATAR (I) = DATARZ (I)

C********** CONUERT TIME FROM ASCII OHARAOTERS TO DECIMAL EQUIUALENT CALL TIMCUT (TIME)

$N K=N C H-48$

C********** CHECK FOR TIME SEQUENCE

IF (TIME 1.NE. TIME) GO TO 400

CXXXXXXXXXX NEXT 3 STATEMENTS CHECK FOR ERRORS IN TIFE ONUERSION IF (NORECS.EO.0) GO TO 68

CHK = TIME-TSAU

IF (CHK) 803,800.68

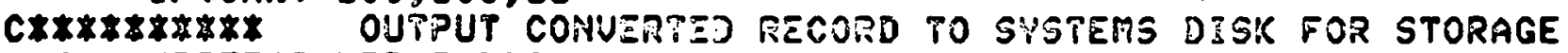

68 URITE (2'NRDAT,ERR=763) TIME, (DAT1 (I), I=1,43), (DAT2 (I), I=1,NX)

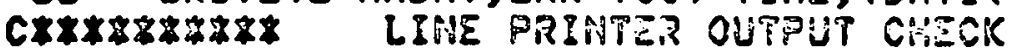
D=FLOAT (NSTRT) 
IF (ILP.EO.1) WRITE (3,59) (DATAR1 (I),I=7,16), NRC,D

CXIX\$X\$सXXX SITE DATA TIME PROFILE OUTPUT TO SCREEN

$Y S=Y S-15$

CALL TPLOT XM, YS, 0,0$)$

URITE $(1,69)$ (DATAR1 (I), I=7,16)

C*****X**** NEXT 5 STATEMENTS CHECK SCREEN LOCATICN FOR. PROPER OUTPUT

69 FORMAT $\left(1 H+, 1\left(\left(2 A 1, \prime^{\prime \prime}\right), 2 A 1,2 X, 2\left(2 A 1, \prime^{\prime}\right), 2 A 1,2 X\right)\right)$

IF (YS.LT. 45.) XM-XM+150.

IF (XM.GT.900.) XM=50.

IF (YS.LT. 45.) JRK = JRK +1

IF (YS.LT.45.) YS=YSAU

IF (YS.LT. 45 . AND.JRK.GT.6) YS $=730$.

C********** INCREMENT THE NUMBER OF OUTPUT RECORDS(NORECS)

NORECS = NORECS+1

TSAU = TIME

C $* * * \$ \$ \$ * * * *$ CHECK FOR BLOCK DATA USED UP, IF (NRC.GE.61) GET ANOTHER BLOCK IF (NRC.GE.61) GO TO 73 


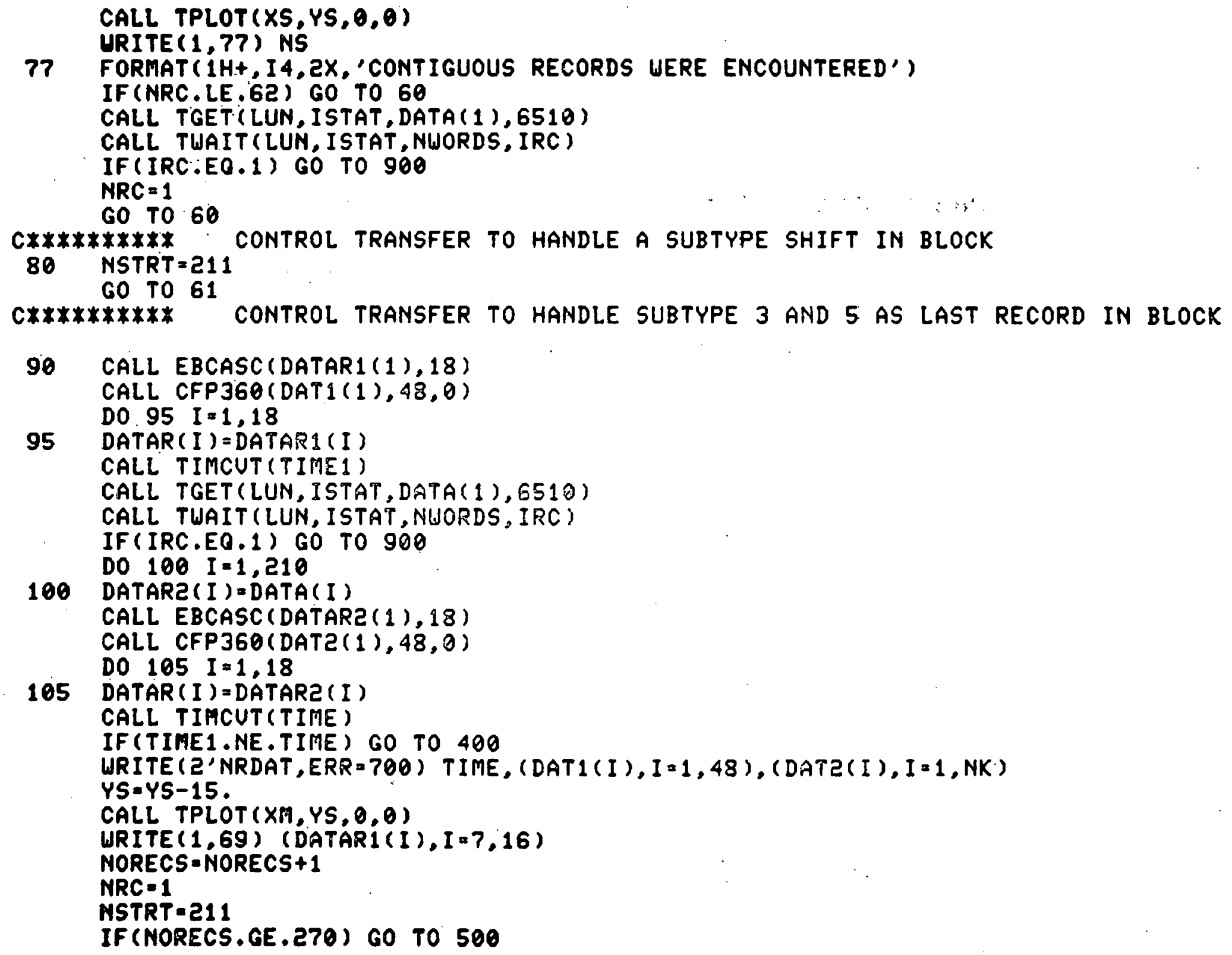




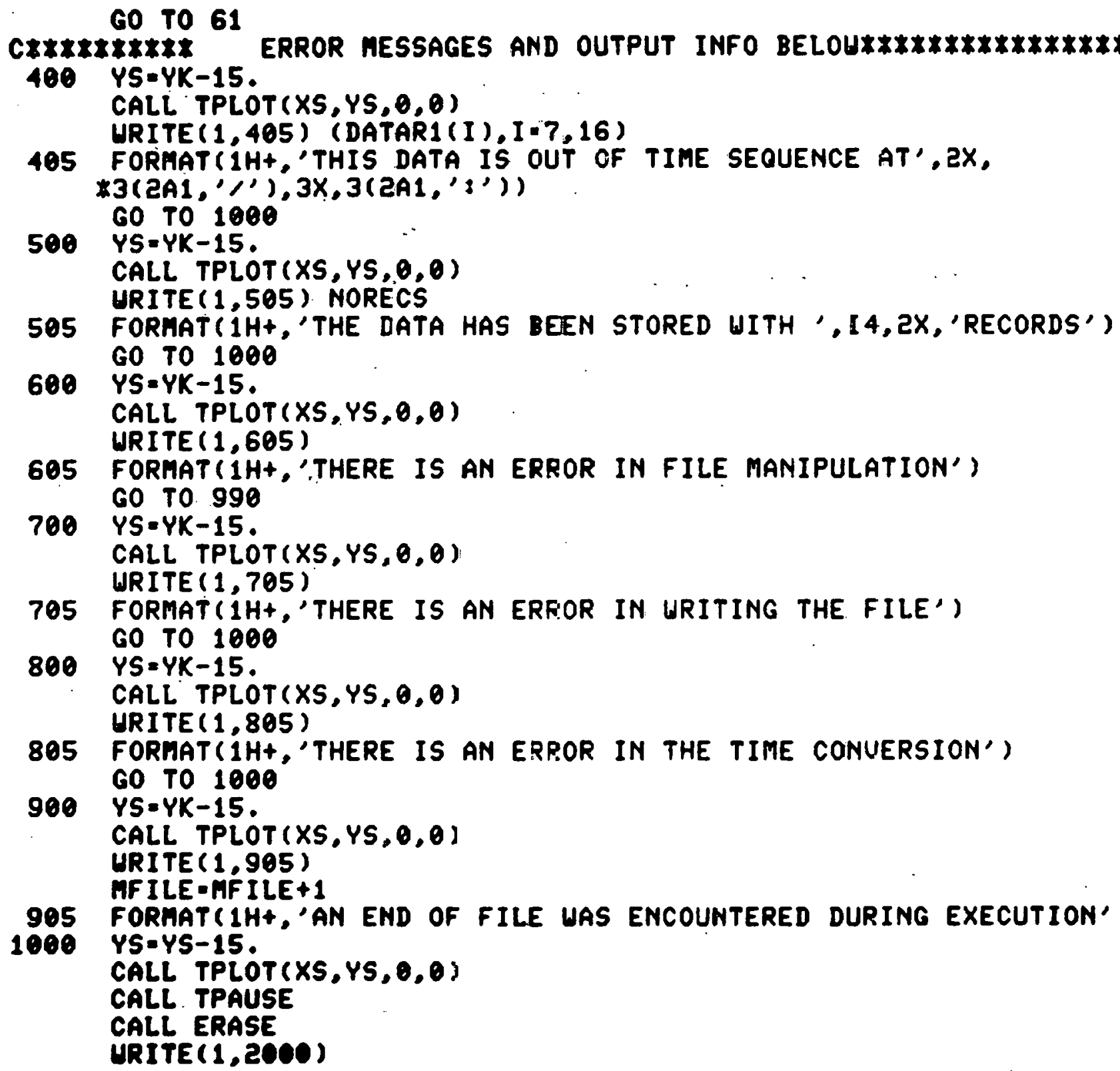


READ (1,2050) IREP

IF (ILP.EQ.1) CLOSE (UNIT =3, DISPOSE = 'PRINT', ERR=9999)

CLOSE (UNIT-2, ERR=9999)

IF (IREP.EO.1) GO TO 2

990 CALL RLND(ISTAT(1))

URITE $(1,1001)$

1001 FORMAT $(/ 1 X$, 'THE TAPE IS BEING REWOUND')

2000 FORMAT( $/ / 1 X$, 'DO YOU UISH TO RETRIEUE MORE DATA ? $\left.(1=Y E S, 2=N O)^{\prime}\right)$

2050 FORMAT (I1)

9999 STOP

PIP) END 
SUBROUTINE TAPFWD (NF ILE, MF ILE, ISTAT, IREP) DIMENSION ISTAT (1)

LUN $=$ ?

IF (IREP.EQ.2.AND.NFILE.EQ.1) RETURN

IF (NFILE.EQ.1) IDIR=3

IF (NFILE.EQ.1) GO TO 60

IF (NFILE-MFILE) $20,20,50$

$20 N F=M F I L E-N F I L E+1$

$I D I R=13$

GO TO 60

50 NF $=$ NF ILE-MF ILE

IDIR $=10$

60 CALL SFUN(LUN, ISTAT,NF, IRC, IDIR)

CALL TWAITLLUN, ISTAT, NUORDS, IRC)

RETURN

END 
SUBROUTINE TIMCUT (TIME)

INTEGER X2 ITIME (3), ITIME1 (6)

LOGICAL*I DATAR (210)

COMHON/TIM/DATAR

$K=11$

$5 \quad M=K-10$

DO $10 \mathrm{~J}=48,5 ?$

IF (DATAR (K) .EQ.J)ICHK = J

10 CONT INUE

$\operatorname{ITIME} I(M)=\operatorname{ICHK}-48$

IF (M.GT.G) GO TO 15

$K=K+1$

$15 \mathrm{~J}=1$

GO TO 5

DO $20 I=1,5,2$

ITIMEI $(I)=\operatorname{ITIME~I~(I)~} * 10$

$\operatorname{ITIME}(J)=\operatorname{ITIME} 1(I)+\operatorname{ITIME} I(I+1)$

20 CONTINUE

$\stackrel{8}{6}$

$T 1=$ (FLOAT (ITIME (3))/60.)

$T 2=(F L O A T(I T I M E(2))+T 1) / 60$.

TIME = (FLOAT (ITIME (1) )+TZ)

PIP) END 
CHK- used for the difference between two consecutive time points

D- real value of starting position in data block for conversion and storage

IDIR- tape function to be performed ( $3=$ rewind, $10=$ forward space files, $13=$ backspace files)

ILP- integer variable for line printer output decision ( $1=$, yes, $2=$ no)

IRC- denotes error status ( $0=$ correct read, $1=$ end of file, $2=$ tape error)

IREP- determines whether want more data ( $1=$ yes, $2=$ no)

IRK- denotes the screen time output column number (1-6)

LUN- logical unit number of tape drive

MFILE- current file number

N1- subscripted variable designating subtype value; used to check for contiguous records

NCH- the number of channels at a site

NF- number of files to space on the IBM 360 tape

NFILE- denotes the tape file number in which the desired date is located

NK- the number of channels of data contained in subtype records 4 and 6

NORECS- the number of output records on the system disk

NRC- the operating record number in the data block from the tape

NRDAT- associate variable for opening direct access file (IFILE) and for outputting to the system disk

NS- the number of contiguous records

NSTOP- stopping position in data block, used with NSTRT (NSTOP=NSTRT +209 )

NSTRT- starting position in data block for conversion and storage; calculated from NRC

NSUB- denotes the number of the subtype

NSUB1- the ASCII code equivalent of the subtype 


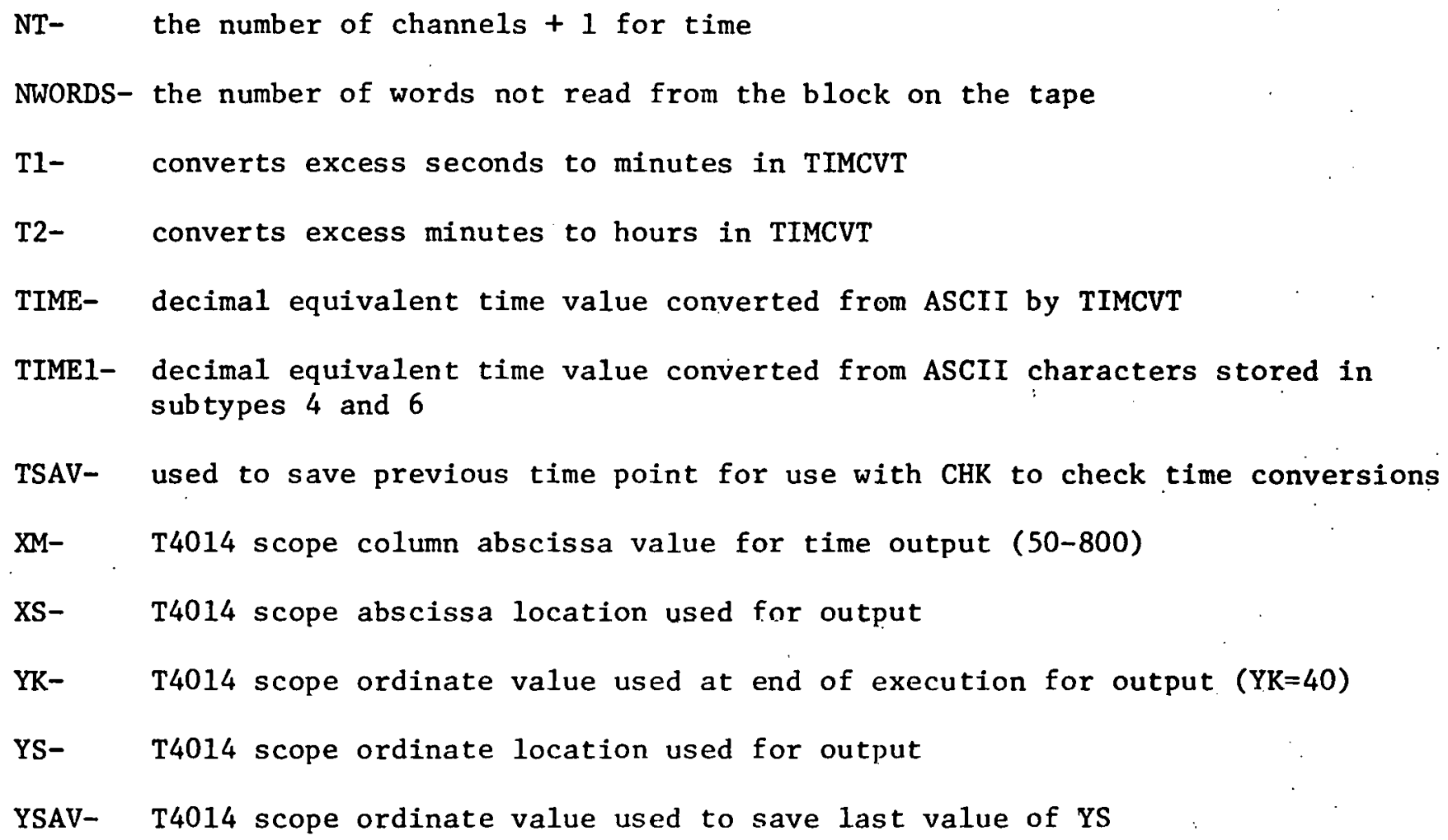

TAPFIL ARRAYS

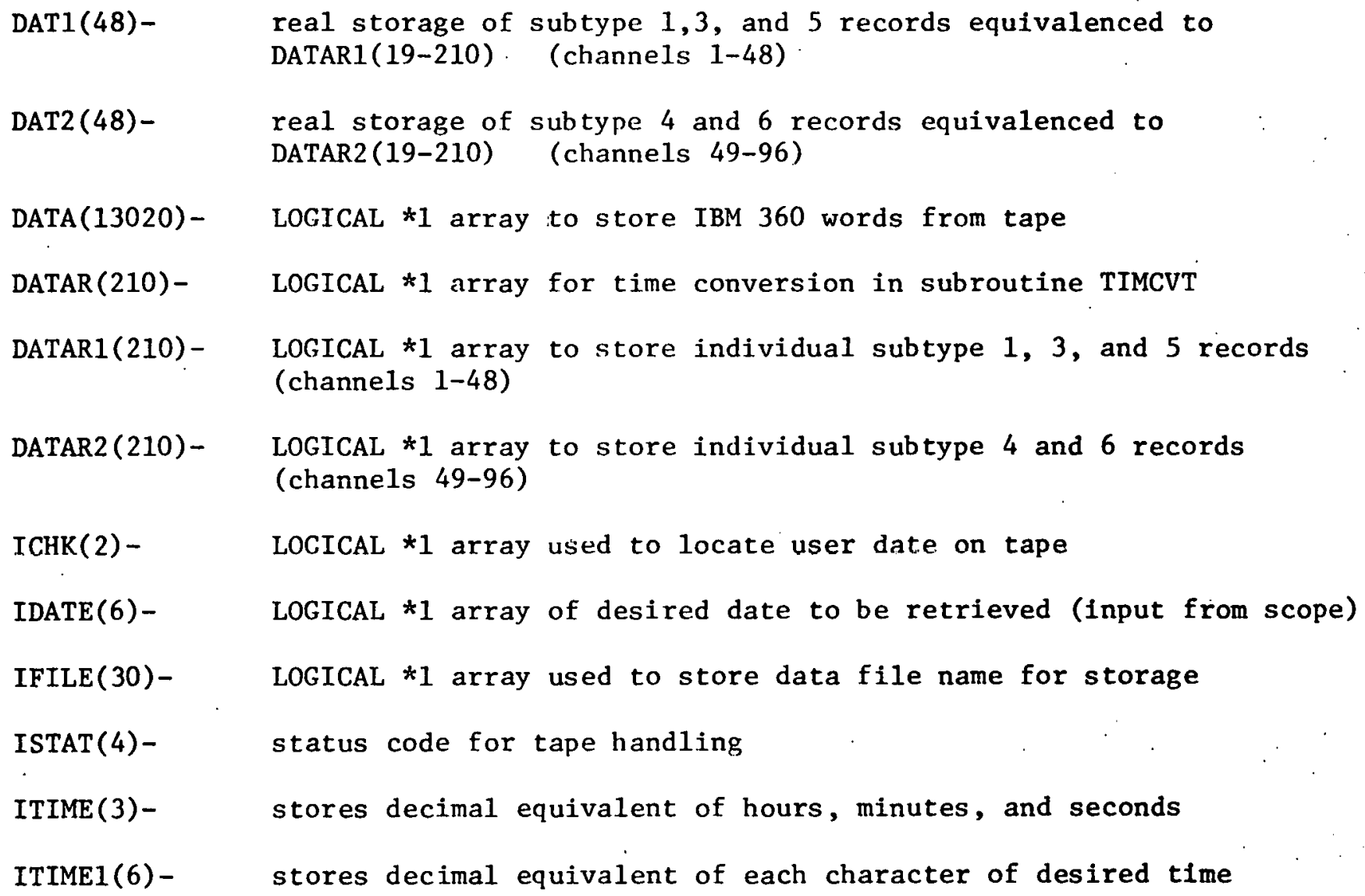


THIS PAGE

\section{WAS INTENTIONALLY \\ LEFT BLANK}


APPTNDIX D

CHPLOT SOURCE LISTING 
SUBROUTINE AUTOSC (XMAX, XMIN, STẌ, RLX, TICX)

INTEGER 4 IA, ISTX, IB, IEX

XMAX .... (INPUT ARGUMENT) MAX. UALUE

XMIN..... (IMPUT ARGUMENT) MIN. UALUE

STX...... (RETURN ARGUMENT) STARTING $X$ UALUE ON AXIS

RLX...... (RETURN ARGUMENT) LENGTH OF AXIS

TICX..... (RETURN ARGUMENT) LENGTH BETWEEN TIC MARKS

RLX $=$ XMAX-XMIN

$0=R L X$

IF (RLX.EO.0.) GO TO 4

$I A=A L O G 10(R L X)$

3 IF (IA) 1,1

ISTX $=X$ XIN $/(10 . \times * I A)$

IB $=$ ISTX

IF (XMIN.LT. 0.) IB = ISTX-1

$I S T X=I B *(10 * * I A)$

IEX $=X$ MAX $/(10 . * * I A)$

$I B=I E X+1$

IF $(X$ XAX.LT.0.) IB = IEX

IEX $=I B X(10 \times X I A)$

RLX $=$ IEX-ISTX

STX = ISTX

TICX $=($ IEX-ISTX $) / 10$

IF $(0$. LE. 10.) TICX $=1$.

GO TO 4

1

CONTINUE

IF (RLX,GE, 1, )GO TO 3

$I A=I A-1$

ISTX $=X M I N /(10 . X X I A)$

Is = ISTX

IF (XNIN.LT.O.) IB-ISTX-1

STX $I B \times(10 . X X I A)$

IEX $=X$ MAX $/(10 . X X I A)$

ID $=I E X+1$

IF (XMAX.LT.O. IIE-IEX

$E X=I B N(10.1 X I A)$ 


\section{$R L X=E X-S T X$}

$T I C X=(10 . * \$ 1 A)$

8 IF (TICX.GE. $\left.\left(R L X / 10_{0}\right)\right) 60$ TOT $T I C X=T I C X+(10 . * * I A)$

GO. TO 8

7 CONTINUE

IF ( (RLX/TICX).GT.4.)GO TO 4 TICX $=T I C X / 2$.

GO TO 7

4 RETURN

PIP)

END 
CHPLOT :

DIMENSION SX1 (6), SX2 (6), SX3(6), SX4(6), SX5(6)

DIMENSION SAU1 (300), SAUZ (300), SAU3 (300), SAU4 $(300)$, SAU5 $(300)$

DIMENSION PID (4),XTITL (4), TIME (300)

COMHON/SX/SX1, $5 \times 2,5 \times 3,5 \times 4,5 \times 5$

COMMON/PID1/PID

COMMON/STOPT/ISTOPT, ISTOPF

COMMON/POINTS/NPT

COMMON/HOWM/NPLT, IFILE, NSCH

COMMON/LUN/IS, IP, IC, ISD

COMMON/UTL1/IFLAGX, XMAX, XMIN

COMMON/UTLC/IFLAGY, YMAX, YMIN

COMMON/NUMBR/SAU1, SAU2, SAU3, SAU4, SAU5, TIME

DATA XTITL/'CLOC','K TI','ME ',' ',

CALL BEGIN(9600)

IS=1

ISTOPT $=0$

ISTOPF $=0$

1 CALL DISPLY

IFLAGX $=0$

IFLAGY $=0$

CALL RETREU

5 CALL PLOT5(PID(1), XTITL(1), SAU1(1), SAUZ(1), SAU3(1), SAU4(1), SAU5(1)

$*$, TIME ( 1 ), NPT, NPT, NPT, NPT, NPT, -1)

Call tPaUse

CALL WATNXT (IR)

ISTOPT $=1$

ISTOPF $=1$

IF (IR.EQ.1) GO TO 1

ISTOPT $=0$

ISTOPF $=0$

IF (IR.EO.3) GO TO 1

ISTOPF $=1$

ISTOPT $=0$

IF.(IR.EO.4) GO TO.I

IF (IR.EO.5) GO TO 10

Call PSCale

GO TO 5

10

STOP.

END 
SUBROUTINE CHSIZE(N)

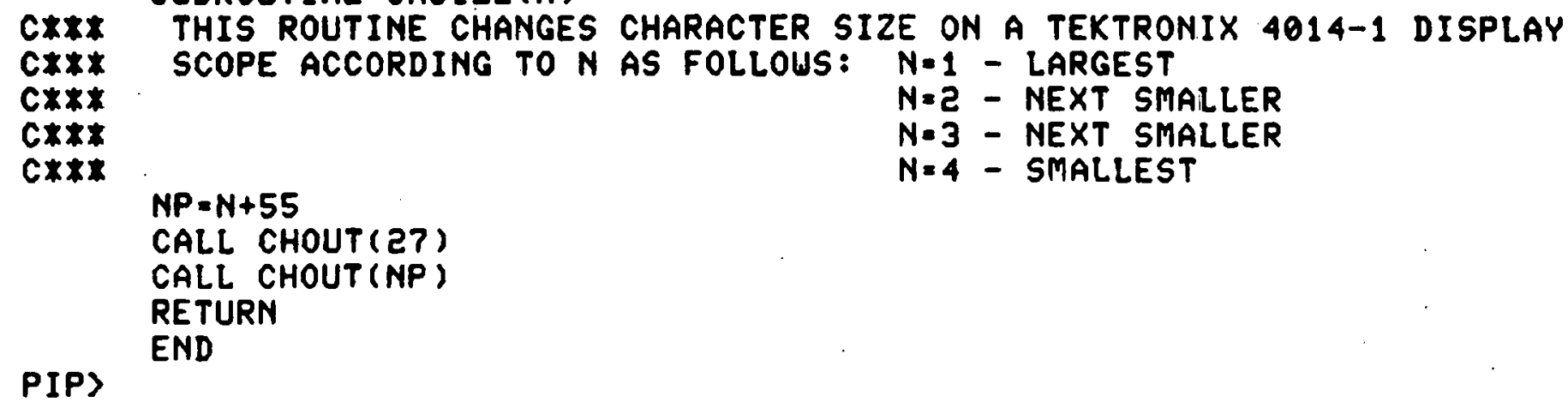


SUBROUTINE DATIN(XS, YS, DATU)

CX** THIS ROUTINE ALLOUS THE USER TO RETRIUE FLOATING POINT DATA FROM

CXXะ THE SCOPE IN G13.6 FORMAT, ONE WORD PER CALL, XS IS THE ABSOLUTE

CXIX SCREEN COORDINATE IN TEKPOINTS, LIKEUISE YS. DATA FROA THE SCOPE

CX** IS RETURNED IN DATH.

COMMON/LUN/IS, IP, IC, ISD

CALL SCALE $(1,0,1,0,0,0,0.0)$

CALL ALPHA

CALL TPLOT $(X S, Y S, \theta, 0)$

READ(IS, 100) DATW

100 FORMAT (G13.6)

RETURN

END

PIP) 


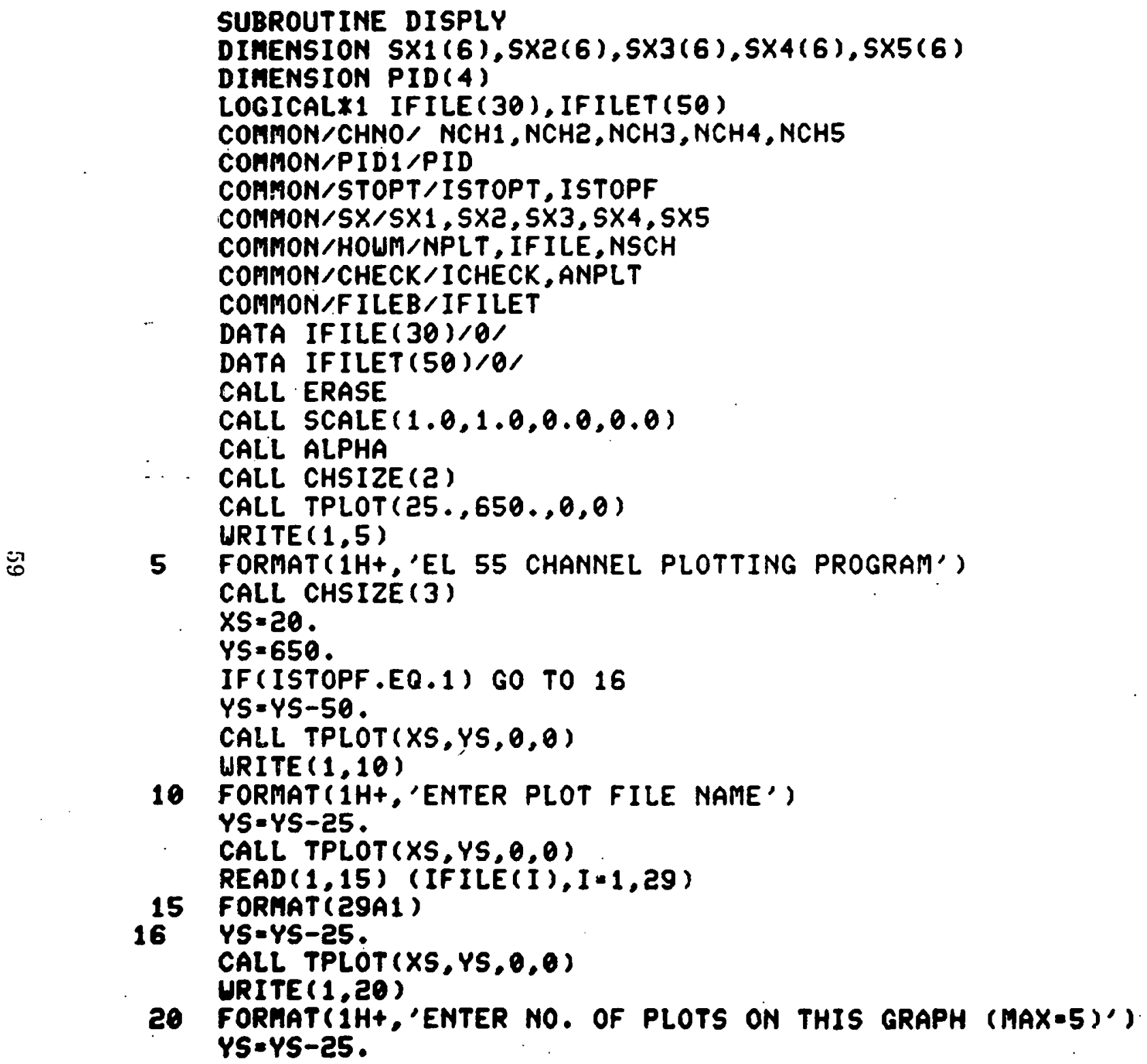


CALL TPLOT(XS,YS,0,0)

READ (1,25) MPLT

25 FORMAT:(I2)

ANPLT = FLOAT (NPLT)

IF(ISTOPT.EO.1) 60 TO 29

YS=YS-25.

CALL TPLOT $(X S, Y S, 0,0)$

WRITE (1,26)

26 FORMAT (IH+, 'ENTER PLOT CAPTION (49 CHARACTERS)')

$Y S=Y S-25$.

CALL TPLOT (XS, YS, 0,0$)$

$\operatorname{READ}(1,27)$ (IFILET $(I), I=1,49$ ).

27

FORMAT ( 49A1)

YS=YS -25 .

CALL TPLOT(XS,YS, 0,0$)$

URITE $(1,43)$

43 FORMAT ( 1 H+, 'ENTER CAPTION FOR LEFT SIDE OF PLOT')

YS=YS- 25 .

CALL TPLOT (XS,YS, 0,0$)$

READ (1, 44) (PID(I), I=1,4)

44

FORMAT ( 4A4)

29 YS=YS-25.

CALL TPLOT $(X S, Y S, 0,0)$

URITE $(1,30)$

30. FORMAT(1H+, 'ENTER CHANMEL NO. AND UNITS')

$K=1$

$R S=X S+40$.

$35 Y S=Y S-25$.

60 TO $(40,45,50,55,60) \mathrm{K}$

10 CALL TPLOT $(X 5, Y 5,0,0)$

41 FORMAT(I2)

CALL TPLOT $(R S, Y S, 0,0)$

42 FORMAT (6A4)

READ(1,42) (SX1(I),I=1,6)

IF (K.EQ.NPLT) GO TO 70

$K=K+1$

60 TO 35 
45 CALL TPLOT(XS, YS,0,0) READ $(1,41)$ NCH2 CALL TPLOT(RS,YS, 0,0 )

READ (1,42) (SX2(I),I=1,6) IF (K.EQ.NPLT)GO TO 70

$K=K+1$

GO TO. 35

50 CALL TPLOT $(X S, Y S, 0,0)$

READ (1,41) NCH3

CALL TPLOT(RS, YS, 0,0 )

$\operatorname{READ}(1,42)(5 \times 3(I), I=1,6)$

IF (K.EQ.NPLT) GO TO 70

$K=K+1$

GO TO 35

55 CALL TPLOT $(X S, Y S, 0,0)$

READ (1,41) NCH4

CALL TPLOT(RS, YS, $\theta, 0$ )

$\operatorname{READ}(1,42) \quad(S \times 4(I), I=1,6)$

IF $(K . E Q$. NPLT $)$ GO TO 70

$K=K+1$

GO TO 35

60 CALL TPLOT (XS, YS, 0,0)

READ $(1,41) \mathrm{NCH} 5$

CALL TPLOT (RS, YS, 0,0$)$

$\operatorname{READ}(1,42) \quad(5 \times 5(I), I=1,6)$

$70 \quad Y S=Y S-25$.

CALL TPLOT (XS,YS, 0,0$)$

IF (ISTOPF.EQ.1) GO TO 75 WRITE (1, 71)

71 FORMAT (1H+, 'ENTER NO. OF CHANNELS AT SITE') YS=YS-25.

CALL TPLOT(XS,YS, 0,0$)$

$\operatorname{READ}(1,41) \mathrm{NSCH}$

YS=YS -30 .

CALL TPLOT (XS,YS, 0,0$)$

75 URITE $(1,72)$

72 FORMAT( 1 H+.'DATA IS BEING RETRIEUED') RETURN

END 
SUBROUTINE PLOTS(PID, UNITS, Y1, YZ, Y3, Y4, Y5, X, NPT1, NPTE, NPT3, NPT4, XNPT5, IG)

C*t*t*

PLOTG BUILDS 5 PLOTS OF DATA ON A STANDARA GRAPH FOR USE IN THE

Cxx* OUICK-LOOK GRAPHICS PROGRAM. PID IDENTIFIES THE NAME OF THE DATA BASE. UNITS IS THE ARRAY CONTAINING THE UNITS OF MEASUREMENT OF THE DEPENDENT PARAMETER. XTITL IS THE ARRAY CONTAINING THE INDEPEDENT PARAMETER UNITS. $X$ AND $Y$ ARE THE ARRAY ELEMENTS FROM THE FIRST ARRAY OF DATA READ IN, CORRESPONDING WITH SYMBOL XKENO. XZ AND YZ ARE THE ARRAY ELEMENTS FROM THE SECOND ARRAY OF DATA, CORRESPONDING WITH SYMBOL XKYNO. NPID IS THE NUMBER OF CHARACTERS TO BE PRINTED FOR PID. NUN IS THE NUMBER OF CHARACTERS TO BE PRINTED FOR UNITS. NXT IS THE NUMBER OF CHARACTERS TO BE PRINTED FOR XTITL. NPXY IS THE NUMBER OF POINTS IN THE FIRST DATA ARRAY, NPXYZ IS THE NUMBER OF POINTS IN THE SECOND DATA ARRAY. IG IS THE GRID LINE UARIABLE, (IG.EO.-1)FOR GRID LINES. (IG.EQ.1) FOR NO GRID LINES.

DIMENSION PID(4), UNITS(4),YI(1),X(1),YZ(1),Y3(1)

DIMENSION $5 \times 1(6), 5 \times 2(6), 5 \times 3(6), 5 \times 4(6), 5 \times 5(6)$

DIMENSION FILET (12)

DIMENSION Y4(1), Y5(1)

COMMON/FILEB/IFILET

COMPON/SX/SX1, SX2, $5 \times 3,5 \times 4,5 \times 5$

COMMON/CHECK/ICHECK, ANPLT

COMMON/LUN/IS, IP, IC, ISD

LOGICAL*1 IFILET(50)

COMMON/UECT/IUECT

EOUIUALENCE (FILET (1), IFILET(1))

DATA IFILET $(50) / 0 /$

10 IUECT $=1$

CALL SSPLOT YY (1),YZ(1),Y3(1),Y4(1),Y5(1),X(1),850.,

*623.,140,.118, ,NPT1,NPT2, NPT3,NPT4,NPT5, IG, IG)

CALL CHSIZE (3)

CALL YLABEL $(10, .700$, PID (1),16)

CALL XLABEL $(420,58$, UNITS $(1), 16)$

CALL SCALE $(1,0,1.0,0.0,0.0)$

CALL TPLOT $(10 . .100 .0,0)$

CALL ALPHA 
59

UKITE $(1,5 Y) \quad(1+1 L E T(1), 1=1,49)$

FORAAT (1H+, 49A1)

NPLT $=I N T$ ( ANPLT)

DO $100 \mathrm{~J}=1$, NPLT

GO TO $(101,102,103,104,105) \mathrm{J}$

101 CALL TPLOT $(634,, 70,0,0)$

CALL UECTOR

CALL TPLOT $(710, .70,, 1,0)$

CALL POINT

CALL ALPHA

CALL XLABEL(753,.70,,5X1(1),24)

GO TO 100

102

CALL TPLOT $(634, .50, .0,0)$

CALL UECTOR

CALL CHOUT(27)

CALL CHOUT (97)

CALL TPLOT $(710, \ldots, 50,1,0)$

CALL POINT

CALL ALPHA

CALL XLABEL $(753,, 50,, 5 \times 2(1), 24)$

בิ

103 CALL TPLOT $(634,030,, 0,0)$

CALL UECTOR

CALL CHOUT(27)

CALL CHOUT(99)

CALL TPLOT $(710, .30,01,0)$

CALL POINT

CALL ALPHA

CALL XLABEL $(753,, 30, .5 \times 3(1), 24)$

GO TO 100

104 CALL TPLOT $(118, .70 ., 0,0)$

CALL UECTOR

CALL CHOUT (27)

CALL CHOUT (100)

CALL TPLOT $(194, .70, .1,0)$

CALL POINT

CALL ALPHA

CALL XLABEL $(237 . .70 \ldots, 5 \times 4(1), 24)$ 


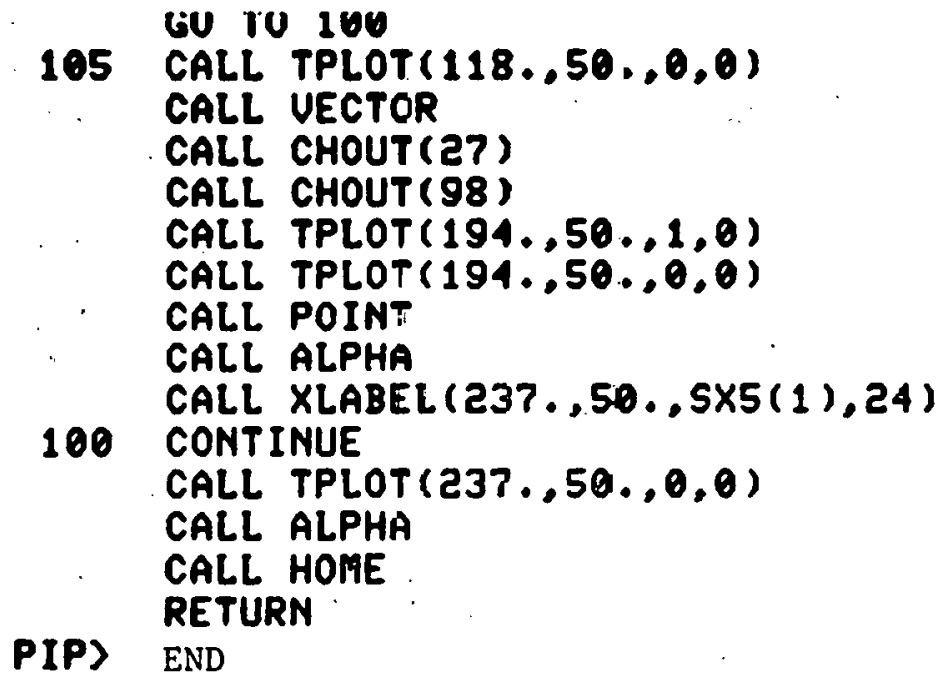


SUBROUTINE PSCALE

COMMON/UTL1/IFLAGX, XMAX, XMIN COMMON/UTLZ/IFLAGY, YMAX, YMIN

CALL ERASE

IF LAGX $=1$

IFLAGY $=1$

$X S=25$.

YS $=600$.

CALL TPLOT(XS, YS, 0,0$)$

URITE $(1,20)$

20 FORMAT ( $I H+$, 'ENTER MAXIMUM AND MINIMUM UALUES FOR $X$ AND $Y$ ')

YS= YS-25.

CALL TPLOT $(X S, Y S, 0,0)$

WRITE $(1,25)$

25 FORMAT(1H+, 'XMAX =')

CALL DATIN $(105$, , YS, XMAX)

CALL ALPHA

$Y S=Y S-25$.

CALL TPLOT(XS, YS,0,0)

URITE $(1,26)$

26 FORMAT ( $1 \mathrm{H}+$, 'XMIN=')

CALL DATIN(105.,YS, XMIN)

CALL ALPHA

$Y S=Y S-25$.

CALL TPLOT (XS, YS, 0,0$)$

WRITE (1,27)

27 FORMAT (1H+, 'YMAX =')

CALL DATIN $(105$, , YS, YMAX)

CALL ALPHA

$Y S=Y S-25$.

CALL TPLOT(XS,YS,0,0)

URITE $(1,28)$

28 FORMAT (1H+ 'YMIN=')

CALL DATIN(105., YS, YMIN)

CALL ALPHA

RETURN

END 
SUBROUTINE RETREU

DIMENSION SAU1 (300), SAU2(300), SAU3(300), SAU4(300), SAU5(300)

DIMENSION DATA $(100)$, TIME (300)

LOGICALX1 IFILE(30)

COMMON/NUMBR/SAU1, SAU2, SAU3, SAU4, SAU5, TIME

COMHON/HOWH/NPLT, IF ILE, NSCH

COMHON/POINTS/NPT

COMMON/CHNO/ NCH1, MCHE, NCH3, NCH4, NCH5

DATA IFILE (30)/0/

$\mathrm{NT}=\mathrm{NSCH}+1$

OPEN (UNIT $=2$, NAME = IF I LE, TYPE $=$ 'OLD', ACCESS $=$ ' DIRECT', $\star R E C O R D S I Z E=N T, A S S O C I A T E U A R I A B L E=N R D A T, E R R=25$ )

NRDAT $=1$

$5 \quad K=1$

$10 \operatorname{READ}(2$ 'NRDAT, ERR=21) (DATA(I), I=1,NT)

TIME (K) = DATA (1)

$\operatorname{SAU1}(K)=\operatorname{DATA}(\mathrm{NCH} 1+1)$

IF (NPLT.LT.Z) GO TO 20

$\operatorname{SAUZ}(K)=\operatorname{DATA}(\mathrm{NCHZ}+\mathrm{L})$

乃

IF (NPLT.LT . 3) GO TO 20

$\operatorname{SAUZ}(K)=\operatorname{DATA}(N C H 3+1)$

IF (NPLT.LT.4) 60 TO 20

$S A U 4(K)=\operatorname{DATA}(N C H 4+1)$

IF (NPLT.LT.5) GO TO 20

$\operatorname{SAUS}(K)=\operatorname{DATA}(\mathrm{NCH} 5+1)$

20 IF (K.LT. 270$) \quad K=K+1$

IF (K.LT.270) GO TO 10

21 NPT $=K-1$

CLOSE (UNIT $=2, E R R=25$ )

25 RETURN

PIP)

END 
SUBROUTINE SSPLOT $Y Y 1, Y Z, Y 3, Y 4, Y 5, X, T P X, T P Y, X 0, Y 0$, NPT1, NPTZ

*, NPT3, NPT4, NPT5; IGX, IGY).

CX** SSPLOT AUTOMATICALLY SCALES THE $X$ AND Y DATA STORED IN ARRAYX AND

C*** ARRAYY TO FIT INTO THE TEKPOINTS AUAILABLE AS SHOLN IN TPX AND TPY.

C*** SSPLOT. THEN DRAUS THE AXIS AND GRID, PLOTS. THE DATA IN ARRAYX

C*** AND ARRAYY AND LABLES THE NUMERICAL UALUES OF THE TIC MARKS ON THE AXES.

C*** XO AND YO ARE ORIGIN LOCATIONS FOR THE GRID IN ABSOLUTE SCREEN

C*** COORDINATES REFERENCED FROM SCREEN $(\theta, \theta)$. IGX AND IGY ARE

C*** INDICATORS FOR GRID LINES ON THE PLOT (.LT.O) OR TIC MARKS

C*** (.GT.B) ON THE OUTPUT PLOT.

DIMENSION Y1 $(300), Y 2(300), Y 3(300), Y 4(300), Y 5(300)$

DIMENSION $X(300)$

COMMON/LUN/IS, IP, IC, ISD

COMMON/CHECK / ICHECK, ANPLT

COMMON/UECT/ IUECT

COMMON/UTL1' IFLAGX, XMAX, XMIN

COMMON/UTL2, IFLAGY, YMAX, YMIN

INTEGER* $4 \mathrm{~N}$

CALL ERASE

$L=1$

IF(IFLAGX.GT.O) GO TO. 11

$X$ MAX $=X(1)$

$X M I N=X(1)$

DO $10 I=1$, NPT 1

IF $(X(I), G T \cdot X M A X) \quad X M A X=X(I)$

10 CONTINUE

11 CALL AUTOSC (XMAX, XMIN, STX, RLX, TICX)

CX** CHECX PLOTTING EFFICIENCY

$N=R L X / T I C X$

DO $12 I=1, N$

IF $(($ STX+TICX).GE.XMIN) GO TO 13

STX-STX+TICX

$R L X=R L X-T I C X$

12 CONTINUE

13 CONTINUE

DO $14 I=1, N$ 
IF ( (STX+RLX-TICX),LE.XMAX) GO TO 16

14

\section{RLX-RLX-TICX}

CONTINUE

16 CONTINUE

INRLX $=R L X / T I C X$

CRLX =INRLXXTICX

IF (CRLX.LT.RLX) INRLX-INRLX+1

RLX = INRLXXTICX+0.1

IF (IFLAGY.GT.O) GO TO 21

C*\$*2* FIND LIMITING $Y$ UALUES FOR LEFT SIDE $* * * * * * *$ $Y \operatorname{MAX}=Y 1(1)$

$Y M I N=Y 1(1)$

NPLT = INT (ANPLT)

DO $17 \mathrm{~J}=1$, MPLT

GO TO $(99,101,102,103,104) \mathrm{J}$

99

DO $18 I=1$,NPT 1

IF (YI (I),GT . YMAX) YMAX=YI (I)

IF (YI I ).LT.YMIN) YMIN=YI(I)

\&

18 CONTINUE

101 DO $19 \mathrm{I}=1$, NPT2

IF (YZ(I).GT. YMAX) YMAX=YZ(I)

IF (YZ(I).LT.YMIN) YMIN=YZ(I)

19. CONTINUE

DO $20 I=1$, NPT3

IF (YZ(I) , GT, YMAX) YMAX =Y3(I)

IF (YZ(I).LT.YMIH) YMIN=YZ(I)

20. CONTINUE

103 DO $200 \quad I=1$, NPT 4

IF $(Y 4(I) . G T$. YMAX) YMAX-Y4(I) IF $(Y 4(I) . L T . Y M I N) \quad Y A I N=Y 4(I)$

200 CONTINUE

104. 00201 I-1.MPT5

IF(YS(I).GT.YMAX) YMAX-YS(I)

IF (YS(I).LT.YHIN) YMIN=YS(I) 
CONTINUE

21 CALL AUTOSC (YMAX, YMIN, STY, RLY,TICY)

CXXX CHECK PLOTTING EFFICIENCY

$N=R L Y / T I C Y$

DO $22 I=1, N$

IF ((STY+TICY).GE.YMIN) GO TO 23

STY $=S T Y+T I C Y$

CONTINUE

DO $25 I=1, N$

IF ( (STY+RLY-TICY), LE, YMAX) GO TO 26

$R L Y=R L Y-T I C Y$

25 CONTINUE

26 CONTINUE

INRLY $=R L Y / T I C Y$

CRLY = INRLY*TICY

IF (CRLY . LT . RLX). INRLY =INRLY+I

$R L Y=I N R L Y * T I C Y+0.1$

C***** CHECK PLOTTING EFFICIENCY *********

IF (CRLYR , LT . RLYR) INRLYR = INRLYR+1

RLYR = INRLYR*TICYR+ . 1

$X F A C T=T P X / R L X$

$Y F A C T=T P Y / R L Y$

$Y O S=Y O$

$Y O H=Y O$

$X 05=X 0$

$X 0=X 0-S T X * X F A C T$

YO=YO-STY $K Y F A C T$

$Y O R=Y O M-S T Y R X Y F A C T R$

IF (YO.GT. (YOS+TPY)) YO=YOS + TPY

30 CALL SCALE (XFACT, YFACT, XOS, YOS)

CALL AXIS $(0,0,0,0, R L X, R L Y, T I C X, T I C Y,-1,-1)$

CALL SCALE (XFACT, YFACT, XO, YO)

CALL POINT

IF (IUECT.GT.O) CALL VECTOR 
$I=1$

NPLT $=I N T$ (ANPLT)

DO $800 \mathrm{~J}=1$, NPLT

INE T= 6

GO TO $(302,301,302,303,304) \mathrm{J}$

300

IF (IFLA ÂX.LT.1) GO TO 299

INET $=1$

DO $38 I=1$, NPT 1

IF $(X(I), G T . X M I N$. AND,YI(I),GT.YMIN) CALL TPLOT $(X(1), Y 1(I), 0,0)$ IF $(X(I), G T . X M I N, A N D, Y 1(I), G T, Y M I N) L=I$

38 CONTINUE

299 IF(INET.LT.1) CALL TPLOT $(X(1), Y 1(1), 0,0)$

DO $39^{\circ} I=L, N P T 1$

IF (X(I) .GT.XPAX.OR.Y1(I).GT.YMAX) GO TO 39

IF (X(I),LT.XMIN.OR.YI(I),LT.YMIN)GO TO 39

CALL TPLOT(X) I $, Y I(I), I, 0)$

39 CONTINUE

CONTINUE

CALL POINT

CALL TPLOTH $0.0,0.0,0,0)$

GO TO 800

301 IF (IFLAGX.LT.1) GO TO 400

INET $=1$

DO $402 I=1$, NPTẼ

IF (X(I),GT.XMIN.AND.YZ(I),GT.YMIN) CALL TPLOT(X(I),YZ(I),0,0) IF (X(I),GT.XMIN.AND.YZ(I),GT.YMIN) $L=I$

402 CONTINUE

400 IF(INET.LT.1) CALL TPLOT $(X(1), Y 2(1), 0,0:$

DO $40 I=L, N P T 2$

CALL UECTOR

CALL CHOUT(2?)

CALL CHOUT (97)

IF (X(I).GT.XMAX.OR.YZ(I).GT.YMAX) GO TO 40

IF (XI I ).LT.XMIN.OR.YZ(I).LT.YMIN) GO TO 40

CALL TPLOT $(X(I), Y Z(I), I, 0)$ 
IF (I.EQ.NPT2) CALL TPLOT(X(NPTZ), YZ(NPTZ), $, 0,0)$

40

CONTINUE

CALL POINT

CALL TPLOT $(0,0,0,0,0,0)$

GO TO 800

302 IF(IFLAGX.LT.1) GO TO 404

INET $=1$

DO $403 I=1$, NPT3

IF (X(I),GT.XMIN.AND.Y3(I),GT.YMIN) CALL TPLOT $(X(I), Y 3(I), 0,0)$

IF $(X(I), G T, X M I N . A N D . Y 3(I), G T, Y M I N) L=I$

403 CONTINUE

404 IF (INET.LT.1) CALL TPLOT $(X(1), Y 3(1), 0,0)$

DO $41 I=L$, NPT3

CALL UECTOR

CALL CHOUT (27)

CALL CHOUT( 99$)$

IF (X(I),GT.XMAX.OR.Y3(I),GT.YMAX) GO TO 41

IF (X(I),LT.XMIN.OR.YZ(I).LT.YMIN) GO TO 41

CALL TPLOT $(X(I), Y 3(I), I, 0)$

41 CONTINUE

CALL POINT

CALL TPLOT $(0,0,0.0,0,0)$

GO TO 800

303 IF(IFLAGX.LT.1) GO TO 406

INET $=1$

DO $405 I=1$,NPT 4

IF (X(I),GT.XMIN.AND.Y4(I),GT.YMIN) CALL TPLOT $X(I), Y 4(I), 0,0)$

IF $(X(I), G T$.XMIN.AND.YA(I),GT.YMIN) $L=I$

405 CONTINUE

IF(X) I ).GT.XMIN.AND.Y4(I),GT.YMIN) GO TO 406

406 IF(INET.LT.1) CALL TPLOT $(X(1), Y 4(1), 0,0)$

DO $42 I=L$;NPT4

CALL VECTOR

CALL CHOUT (2.7)

CALL CHOUT (100)

IF (X(I),GT.XMAX.OR.Y4(I).GT.YMAX) GO TO 42 
IF(X(I).LT.XMIN.OR.Y4(I),LT.YMIN) GO TO 42

CALL TPLOT(X(I),Y4(I),I,O)

42

IF (I.EO.NPT4) CALL TPLOT $(X(N P T 4), Y 4(N P T 4), 0,0)$

CONTINUE

CALL POINT

CALL TPLOT $(\theta, 0,0.0,0,0)$

GO TO 800

304 IF (IFLAGX.LT.1) GO TO 408

INET $=1$

DO $407 I=1$, NPT5

IF (X(I),GT.XMIN.AND.YS(I),GT.YMIN) CALL TPLOT $(X(I), Y 5(I), 0,0)$

IF (X(I),GT . XMIN.AND.YS(I),GT.YMIN) $L=I$

407 CONTINUE

IF (X(I),GT.XMIN.AND.YS(I).GT.YMIN) GO TO 408

408 IF(INET.LT.1) CALL TPLOT $(X(1), Y 5(1), 0,0:$

DO $43 I=L, M P T 5$

CALL UECTOR

CALL CHOUT (27)

CALL CHOUT (98)

IF (X(I).GT,XMAX,OR.Y5(I),GT.YMAX) GO TO 43

IF (X(I).LT.XMIN.OR.YS(I).LT.YMIN) GO TO 43

CALL TPLOT $X(I), Y 5(I), I, 0)$

43

IF (I.EQ.NPT5) CALL TPLOT (X(NPTS), Y5(NPTS),0,0)

CONTINUE

CALL POINT

CALL TPLOT $(0,0,0.0,0,0)$

800

$L=1$

C*** DATA PLOTTING IS COMPLETE, LABLE SCALES ON AXES

CALL ALPHA

CALL SCALE $(1.0,1.0,0.0,0.0)$

CALL CHSIZE (3)

$X O=X O S$

$Y O=Y O S$

$T Y=S T Y+R L Y$

$Y L=Y O$

$X L=X 0-121.0$

50 CALL TPLOT $(X L, Y L, 0, \theta)$

URITE(IS,100) STY 


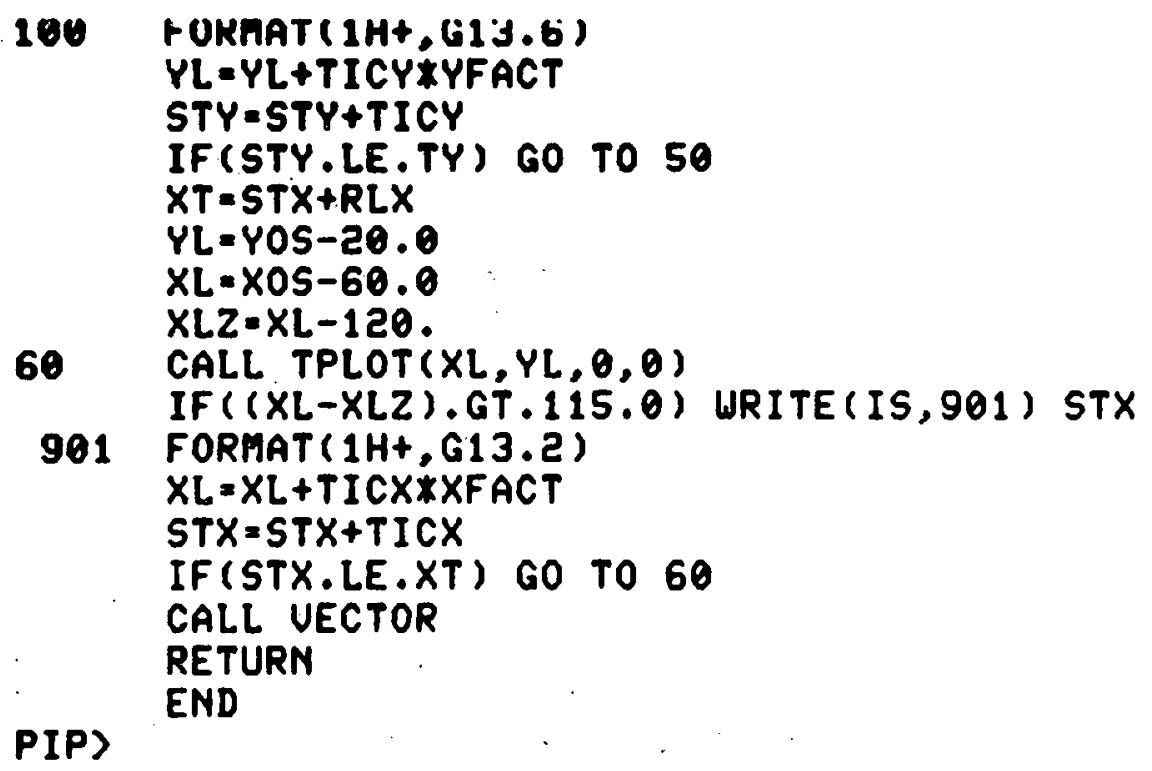




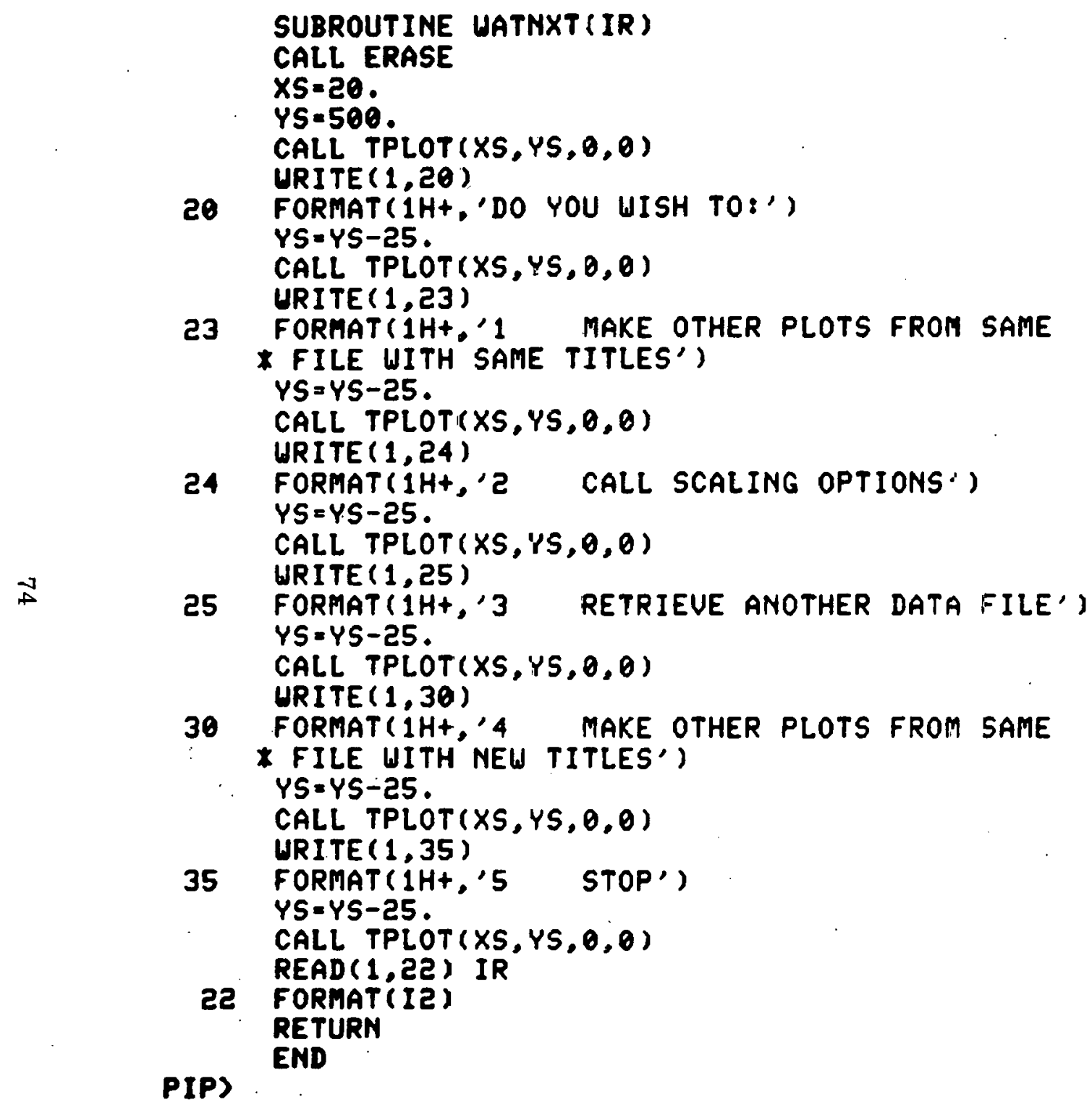

25 FORMAT ( $1 \mathrm{H}+, 3$ RETRIEUE ANOTHER DATA FILE') $Y S=Y S-25$. 
SUBROUTINE XLABEL(XS, YS, ARRAY, NPA)

$\cot +x$

CxIx

THIS ROUTINE OUTPUTS TEXT IN THE +X DIRECTION ON THE 4014 SCOPE.

Cx*x: XS\&YS ARE ABSOLUTE SCREEN COORDINATE LOCATIONS IN TEKPOINTS.

ARRAY IS THE FIRST LOCATION IN WHICH THE TEXT ARRAY IS STORED

C*A* (4 CHARACTERS/LOCATION), NPA IS THE NUMBER OF CHARACTERS TO BE

C** OUTPUT TO SCOPE LUN $=$ IS.

COMMON/LUN/IS, IP, IC, ISD

DIFENSION ARRAY (1)

CALL SCALE $(1,0,1,0,0,0,0.0)$

CALL ALPHA

CALL TPLOT (XS,YS, 0,0$)$

C*** NOTE: PDP ISSUES LINE FEED COMMAND BEFORE URITING, USER MUST

C*** ADJUST YS ACCORDINGLY, THUS FORMAT CONTAINS $1 H+$ AND YS IS START $N W=N P A / 4$

IF ( (NPA-NW*4), NE. 0$) \quad N W=N W+1$

WRITE (IS, 100) (ARRAY (I),I=1,NW)

100

FORMAT (1H+, 30A4)

RETURN

जै

PIP)

END 
SUBROUTINE YLABEL (XS, YS, ARRAY, NPA)

CXXX THIS ROUTINE WILL UERTICALLY PRINT A CHARACTER STRING ON THE

C*** T4014 STARTING AT ABSOLUTE LOCATION (XS,YS) IN TEKPOINTS. DATA

CXX* TO BE PRINTED ARE STORED IN ARRAY WITH 4 CHARACTERS TO THE WORD.

CX** NPA IS THE NUMBER OF CHARACTERS TO BE PRINTED.

COMMON/LUN/IS, IP, IC, ISD

DIMENSION ARRAY $(1), X(1)$

LOGICAL*1 ]X(4), IBLK

EQUIUALENCE $(X(1), I X(1))$

DATA IBLK/IH,

$N U=N P A / 4$

IF ( (NW*4-NPA) .EQ.0)GO TO 20

$X(1)=A R R A Y(N W+1)$

DO $10 \quad I=1,4$

IF ( (NW*4+I), LE .NPA) GO TO 10

$I X(I)=I B L K$

10 CONTINUE

ARRAY $(N W+11=X(1)$

$\vec{a}$

$N W=N W+1$

20 CALL SCALE $(1,0,1.0,0.0,0.0)$

CALL ALPHA

CALL TPLOT:XS,YS, 0,0

$30 \quad I C=1$

$X(1)=A R R A Y(I C)$

DO $40 \quad I=1,4$

CALL CHOUT (IX(I))

CALL CHOUT(10)

CALL CHOUT(8)

48

CONTINUE

$I C=I C+1$

IF (IC.LE.NW $) G 0$ TO 30

RETURM

PIP) 


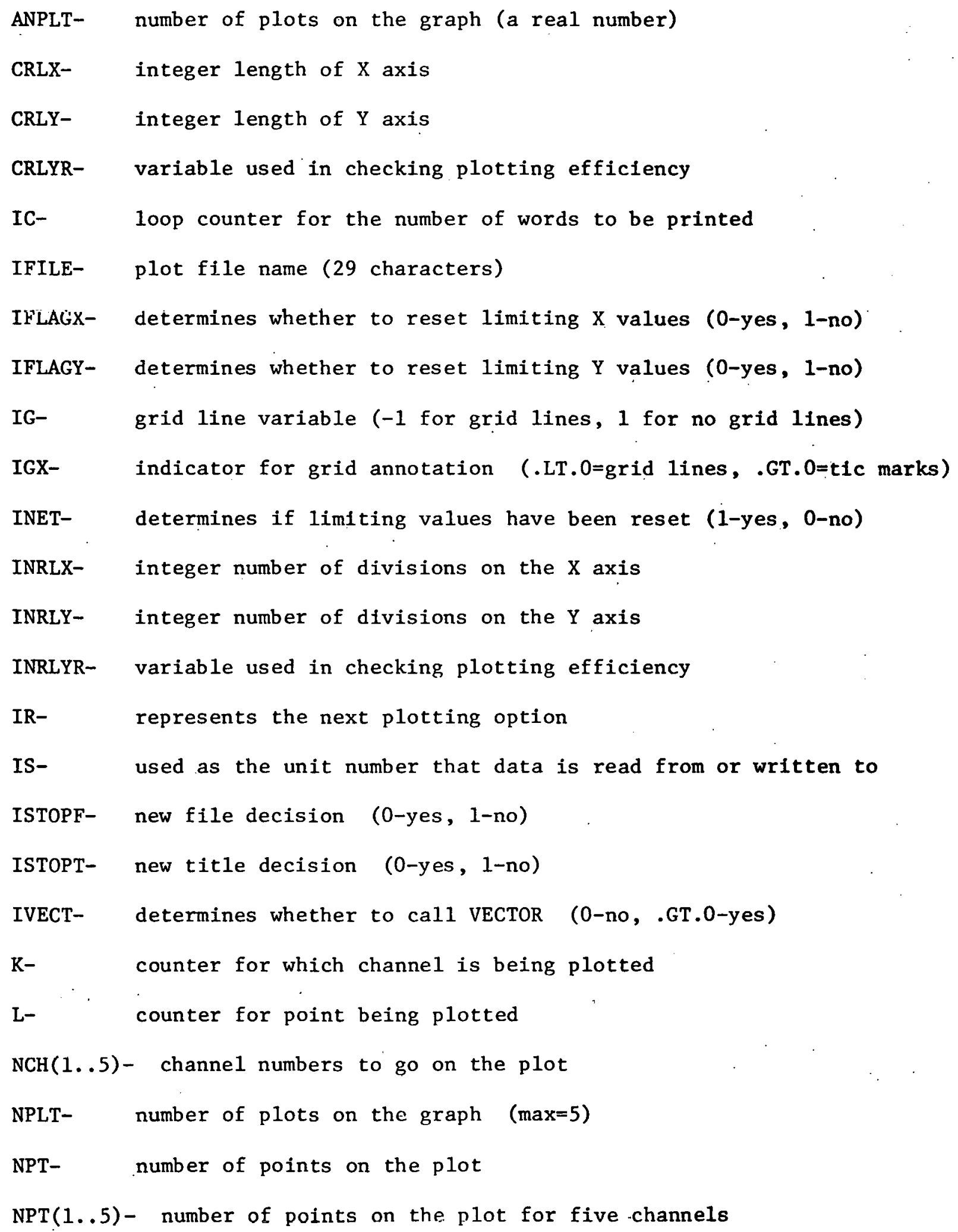




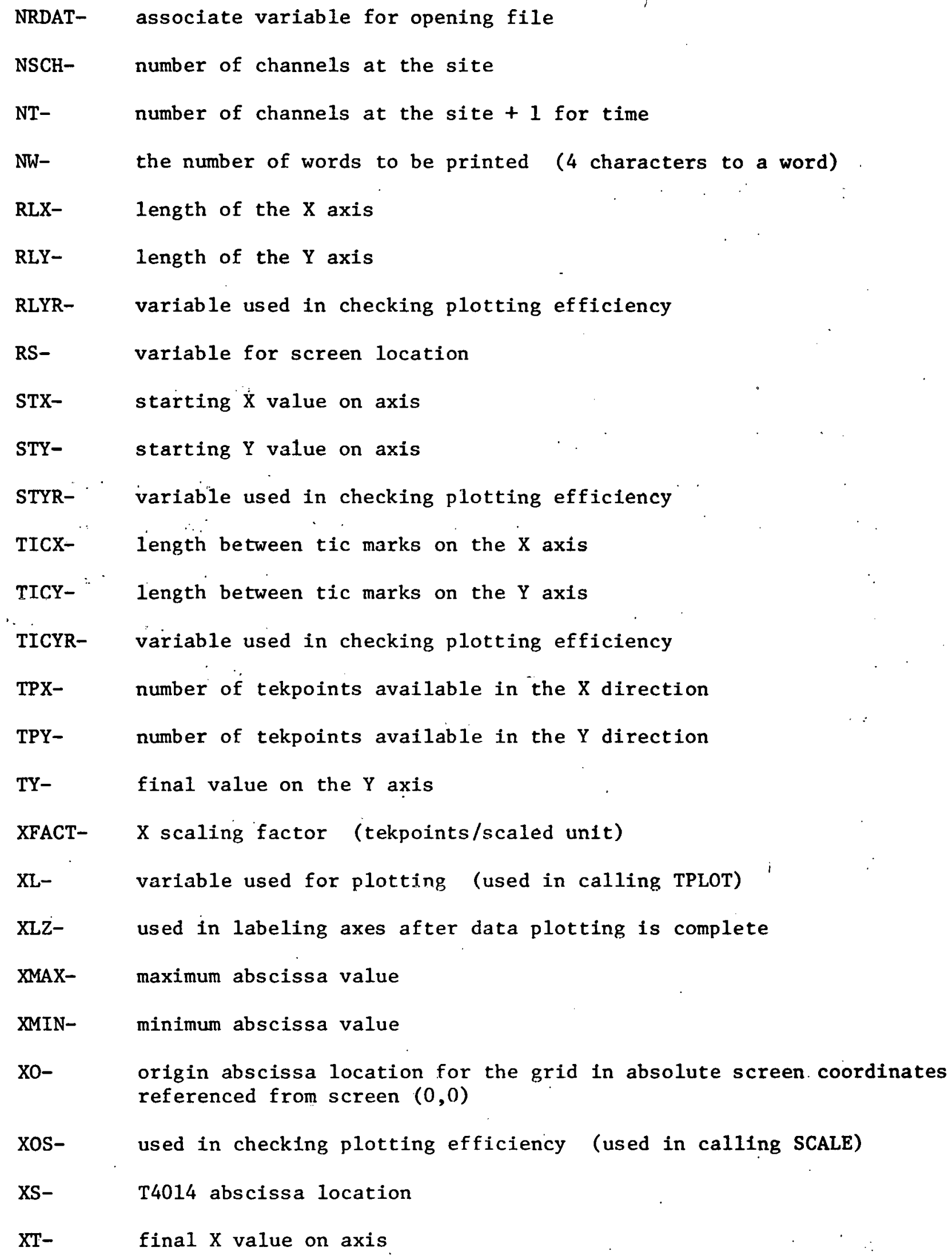




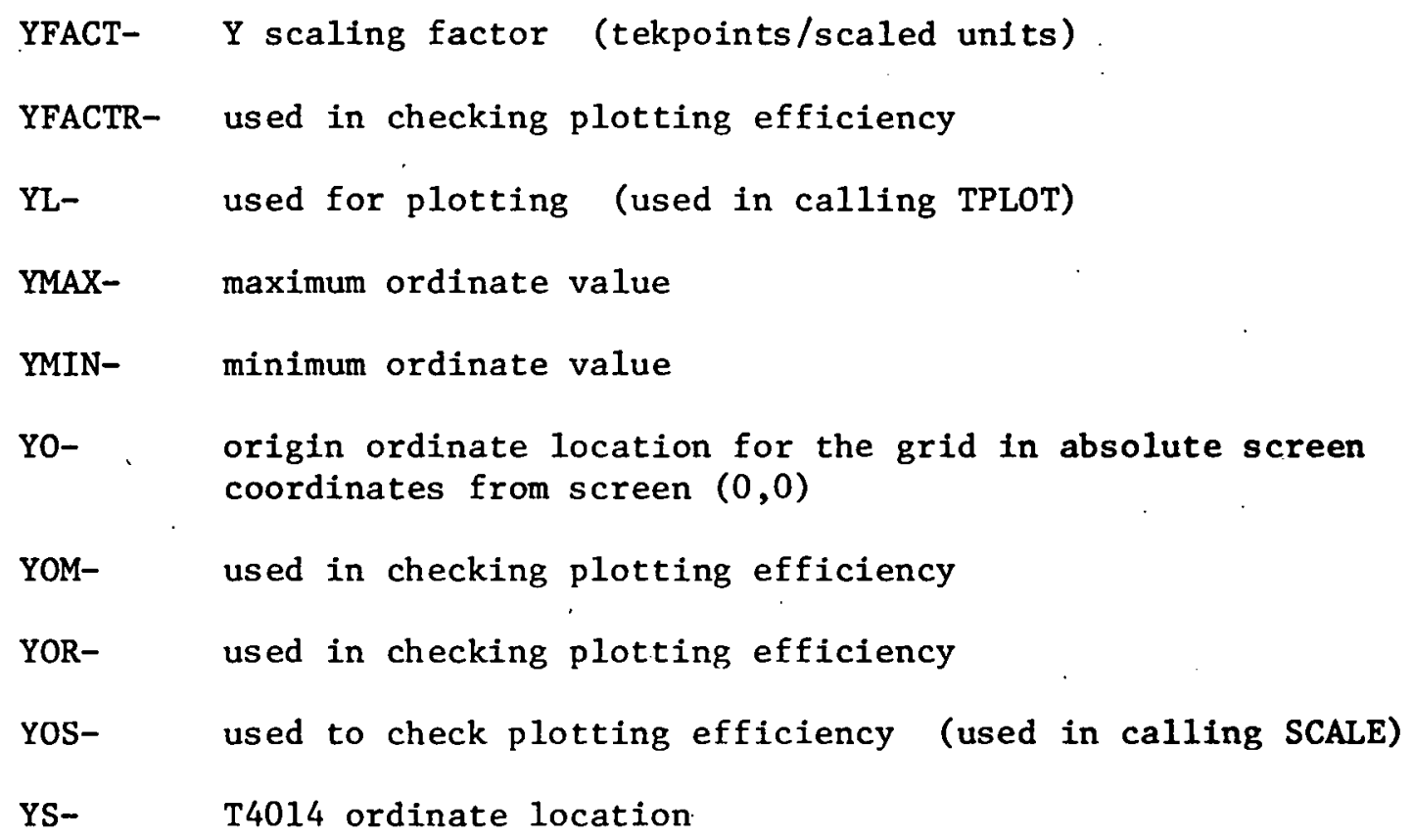

\section{CHPLOT ARRAYS}

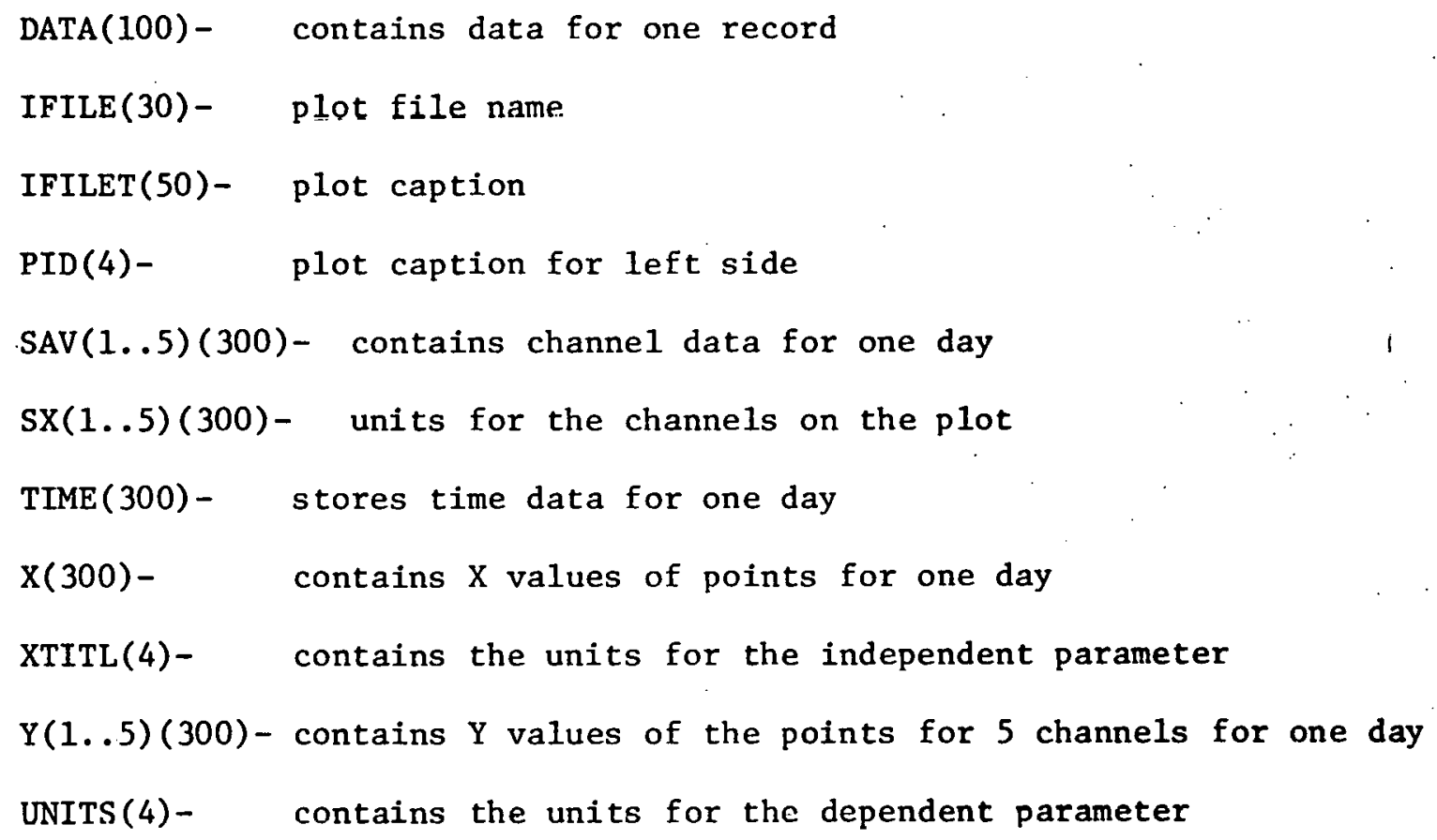




\section{THIS PAGE}

\section{WAS INTENTIONALLY LEFT BLANK}


APPENDIX E

WRTCNL SOURCE LISTING

䔳 
SUBROUTINE INPUT (ICHNLS, MCH, NOUT, XNAFES, XNUM)

DIMENSION ICHNLS (1),XNAMES (1), XNUM(1)

LOGICALX1 IFILE( 30 )

COMMON/FILE/IFILE

URITE $(1,10)$

10 FORMAT(T2, 'ENTER NO. OF CHANNELS AT SITE')

15 READ (1,15)

URITE (1,20)

20 FORMAT(T2, 'ENTER THE NO. OF CHANNELS TO BE OUTPUT (10 MAX'')

READ $(1,15)$ NOUT

URITE (1,25)

25 FORMAT(T2,'ENTER THOSE CHAMMELS NOS. AS: $01,02,03, \ldots \ldots$, )

READ (1,30) (ICHNLS ( I), I =1, NOUT)

30 FORMAT $(10(I 2,1 X))$

URITE $(1,35)$

35 FORMAT (T2, 'ENTER MEASUREMENT TYPE; AND NUMBER, AS: XTT100,EP101, UW100,....." NOTE: PROGRAM EXPECTS 2 LETTER * IDENTIFICATION OF MEASUREMENT TYPE- $"$, SINGLE LETTER MEASUREMENT * TYPES SUCH AS TEMPERATURE" " SHOULD BE INPUT AS TT,UW,ETC.') READ $(1,40)$ (XNUMA (1),XNAMES (I), I=1, NOUT)

40 FORMAT $(10(A 2, A 3,1 X))$

URITE $(1,45)$

45. FORMAT(T2, 'ENTER THE DATA FILE NAME OF THE STORED DATA') READ (1,50) (IFILE(I), I=1,29)

50 FORMAT (29A1)

RETURN

END

PIP) 
SUBROUT INE OUTPUT (ICHNLS, DATA, XNAMES, XNUM, NOUT, NCH) DIMENSION ICHNLS (1), XNAMES (1),XNUM(1),DATA (1), DAT (96) LOGICALE1 IFILE( 30$)$ COMMON/FILE/IFILE

$J=1$ MRDAT $=1$

$I C N T=1$

3 FORMAT $(5 X, 29 A 1)$

WRITE $(3,1)$ (XNUM ( I ), XNAMES ( I ), I = 1, NOUT)

1 FORMAT (5X, 'TIME', $4 X, 10(3 X, A 2, A 3,3 X) / /)$

$2 \quad \operatorname{READ}(2$ 'NRDAT, END $=30, E R R=30)(\operatorname{DAT}(I), I=1, N C H+1)$

DO $10 I=1$, NOUT

$J J=I C H N L S(I)+1$

10 DATA ( I ) = DAT ( JJ)

IF(ICNT . LE. 50$)$ GO TO 20

WRITE $(3,4)$

4 FORMAT (1H1)

WRITE (3,3) IFILE

URITE $(3,1)$ (XNUM (I), XNAMES (I),I I, NOUT)

ICNT $=1$

20 NRDAT $=$ NRDAT +1

URITE (3,15) DAT (1), (DATA(I), I =1, NOUT)

15 FORMAT (F10.4,10F 11.2)

$I C N T=I C N T+1$

$j=\mathrm{J}+1$

IF (J.GT.270) GO TO 30

GO TO 2

30 CLOSE (UNIT =3,DISPOSE = 'PRINT', ERR=900)

900 RETURN

PIP)

END 
WRTCNL :

DIMENSION DATA $(10), \operatorname{ICHNLS}(10), \operatorname{XNAMES}(10), \operatorname{XNUM}(10)$

LOGICALK1 IFILE(30)

COMMON/FILE/IFILE

OPEN (UNIT = 3, NAME = 'PRT . LST', TYPE = 'NEU', ERR=900)

CALL ERASE

CALL INPUT (ICHNLS(1),NCH, NOUT, XNAMES (1), XNUM(1))

NT $=\mathrm{NCH}+1$

OPEN (UNIT $=2$, NAME = IFILE, TYPE = 'OLD', ACCESS = 'DIRECT',

*RECORDSIZE = NT, ASSOCIATEUARI ABLE = NRDAT, ERR = 900 )

CALL OUTPUT (ICHNLS (1),DATA(1),XNAMES (1),XNUM(1),NOUT,NCH)

900

CLOSE (UNIT $=2, E R R=900$ )

900 STOP

PIP) END 
WRTCNL VARIABLES

ICNT- line counter (50 lines/page)
NCH- $\quad$ number of channels at the site
NOUT- number of channels to be output
NRDAT- associate variable for opening IFILE
NT- $\quad$ number of channels at the site +1 for time

WRTCNL ARRAYS

DAT(96)- array to store data for time and channels

DATA(1)- stores data for each channel to be output

ICHNLS(10)- array of channel numbers to be output

IFILE(30)- data file name of stored data

XNAMES(10)- array of measurement numher.

$\operatorname{XNUM}(10)-\quad$ array of measurement type (TT,WW, etc.) 


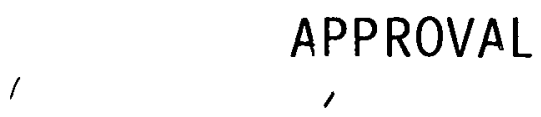

\title{
THREE COMPUTER CODES TO READ, PLOT, AND TABULATE OPERATIONAL TEST-SITE RECORDED SOLAR DATA
}

\author{
By
}

Stephen D. Stewart, Robert J. Sampson, Jr., Richard E. Stonemetz, and Sandra L. Rouse

The information in this report has been reviewed for technical content. Review of any information concerning Department of Defense or nuclcar energy activities or programs has been made by the MSFC Security Classification Officer. This report, in its entirety, has been determined to be unclassified.

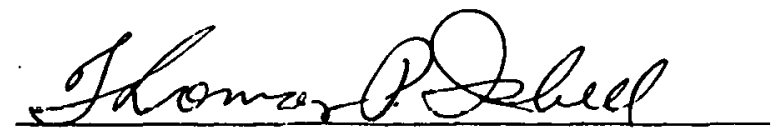

THOMAS P. ISBFLL

Director, Systems Analysis and Integration Lab.

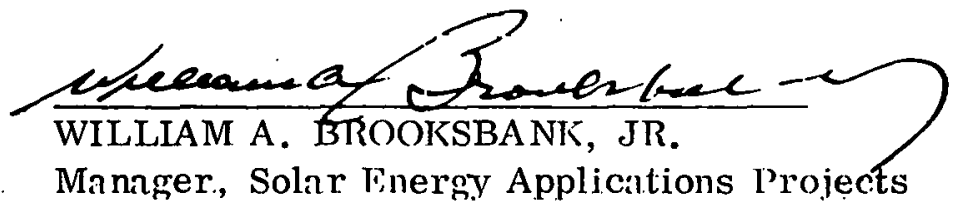

